\title{
COPERNICUS
}

\section{Clinical Medicine Review}

Published: October 22, 2018

Citation: Zhang D. et al. (2018) A

Brief Review on Structure-Bioactivity Relationship Study of Ophiobolins and Derivatives. The Clinical Medicine Review

\section{DOI: https://doi.org/10.31296/cmr.8}

\section{Corresponding Author:}

Dahai Zhang

Email: dahaizhang@ouc.edu.cn

Keywords: Ophiobolin and Derivatives, Bioactivity, Ophiobolin and 6-epi-ophiobolin, Structure- bioactivity relationship, Steric hindrance.

The study presented in the manuscript was supported by the OUC-AU joint projects.

\section{Copyright: (c) (1) \$}

(C) 2018 Copernicus Publishing

This open access article is distributed under the terms of the Creative Commons Attribution Non-Commercial License.
REVIEW ARTICLE

\section{A Brief Review on Structure-Bioactivity Relationship Study of Ophiobolins and Derivatives}

\author{
Qing Ren, Zonglin Yang, Ting Zhang, Xianguo Li, \\ Dahai Zhang
}

\section{Author affiliations:}

Key Laboratory of Marine Chemistry Theory and Technology (Ocean University of China), Ministry of Education, Qingdao, 266100, Shandong, PR China

\section{Abstract}

Ophiobolins show a broad-spectrum inhibitory activity against nematodes, fungi, bacteria, and cytotoxic activity. Now many ophiobolin and their derivatives have been identified, nevertheless, there are few studies on structure-activity relationships for this class of compound. This review aims at summarizing published researches of ophiobolins and their derivatives, including the source, structure, bioactivity, the mode of action and the possible factors that cause the different bioactivity. In view of the fact that the activity of ophiobolins were generally higher than 6-epi-ophiobolins, ophiobolin $\mathrm{O}, \mathrm{K}$ and 6-epi-ophiobolin $\mathrm{O}, \mathrm{K}$ were studied as an example. The geometries, bond lengths, bond orders of the four compounds have been investigated at B3LYP/6-31+G(dip) level by density functional theory (DFT). The DFT analysis show that the ophinbolins steric of function group related to $C$ (7) were much lower than 6 -epi-ophiobolins, it suggested that $\mathrm{C}$-H was the key bioactive group. The low steric reactive function group can be made to maximize contact with the target and thereby enhance the biological activity. It proposed a new pathway for the design and synthesis of the active molecule. 


\section{Diversity of ophiobolins}

Ophiobolins are naturally occurring sesterterpenes characterized by an unusual tricyclic 5-8-5 ring system, some of them have an extra ring incorporated, forming different types of tetra-cyclic structures ${ }^{[1-3]}$. Ophiobolin A was the first member isolated from Ophiobolus Miyabeanus ${ }^{[4]}$, and characterized independently by Canonica et al. ${ }^{[5]}$ and Nozoe et al. ${ }^{[6]}$. Currently, ophiobolin A to ophiobolin W and many analogues were isolated and identified, these include ophiobolin B from Bipolaris ory$z a e^{[7]}$, ophiobolin C from Bipolaris zizanie ${ }^{[6]}$, ophiobolin D from Cephalosporium caerulens $^{[8-9]}$, ophiobolin E from Drechslera gigantean $^{[10]}$, ophiobolin $\mathrm{F}$ from Bipolaris maydis $^{[11]}$, ophiobolin $\mathrm{G}$ and $\mathrm{H}$ from Aspergillus ustus ${ }^{[12]}$, ophiobolin I and J from Drechslera oryzae ${ }^{[13]}$, ophiobolin $\mathrm{K}$ from Aspergillus ustus ${ }^{[14]}$, ophiobolin $\mathrm{L}$ form $B$. maydis $^{[2]}$, ophiobolin $\mathrm{M}$ from Cochliobolus heterostrophus ${ }^{[15]}$, ophiobolin $\mathrm{O}$ from Aspergillus ustus ${ }^{[16]}$,ophiobolin P-T from Ulocladium $s p^{[17]}$, ophiobolin U-W from Aspergillus ustus ${ }^{[18]}$. Among most of them were isolated from land sources, while some of them were produced by marine microorganisms ${ }^{[19]}$. In addition, it has been proved the production of ophiobolins and derivatives by the fungi seems to change with the culturing conditions ${ }^{[2]}$, ophiobolin can also be degenerated into derivatives in culture media ${ }^{[20]}$.

\section{Biological actions of ophiobolins}

Ophiobolins and their derivatives have good bioactivities, such as Anticancer, Nematocidal Activity, Apoptosis-inducing, Herbicidal, Antifungal and Antimicrobial activities ${ }^{[21-23]}$, some of them have been applied in clinic. Except for bioactivity research, relevant work has been carried out to find out the active mechanism, including the synthesis of ophiobolin ${ }^{[24]}$, the construction of core unit like 5-8 bicyclic systems, 5-8-5, 5-8-6-5 rings and spirocyclic CD-ring moiety ${ }^{[25-29]}$.

At present, The research of bioactivities of ophiobolins and derivatives mainly covers the antitumor activities (cytotoxicity), phytotoxicity, antifungal and antimicrobial activities. The mechanism of action on cell death can be triggered by a range of intracellular stresses such as DNA damage, oxidative stress, cytosolic $\mathrm{Ca}^{2+}$ overload and the accumulation of misfolded proteins ${ }^{[30]}$, While it is still a challenge to understand exactly the mechanism of action of ophiobolin, such as how the composite molecule inhabits or kills cancer cells. Among them, ophiobolin A was widely studied for its significant activities.

\subsection{Antitumor activities (Cytotoxicity).} Ophiobolin A showed cytotoxicity in the L1210 cell line ${ }^{[31]}$, inhibited solid and haematological cancer cell proliferation, induced apoptosis and inhibited cell cycle progression in MDA-MB-231 cancer cells ${ }^{\text {[32] }}$. Ophiobolin A can be incorporated into novel chemoembolization particles for the reduction in cell viability of rhabdomyosarcoma cancer (RD) cells ${ }^{[33]}$, also can inhibit growth even induce cell death of several mammalian cancer cell lines irrespective of their multidrug resistance phenotypes and their resistance levels to pro-apoptotic stimuli ${ }^{[20]}$. Ophiobolin A strongly reduced cell viability of melanoma $\mathrm{A} 375$ and $\mathrm{CHL}-1$ cell lines, by affecting mitochondrial functionality ${ }^{[34]}$. Ophiobolin A inhibited the proliferation and migration of GBM cells, 
by inhibiting big conductance $\mathrm{Ca}^{2+}$-activated $\mathrm{K}^{+}$channel activity, also induced paraptosis-like cell death in GBM cells, by the swelling and fusion of mitochondria and/or the endoplasmic reticulum of GBM cells ${ }^{[35]}$. Ophiobolin A reacts with the ethanolamine head group of phosphatidylethanolamine (PE) in human cells and form pyrrole-containing covalent cytotoxic adducts, these adducts lead to lipid bilayer destabilization. At the same time, the genetic inactivation of de novo synthesis of $P E$ can reduce cellular $P E$ levels, then mitigate cytotoxicity of ophiobolin $A^{[36]}$. Ophiobolin A lead to an arrest of the cell cycle and alter the intracellular partitioning of glutathione between the nuclei and cytoplasm of TBY-2 cell ${ }^{[37]}$. Ophiobolin A shows the acute effect on HO-mediated inflammatory processes, caused a significant elevation in the concentrations of IL- 6 and TNF- $\alpha$, increased MPO activity and decreased $\mathrm{HO}$ enzyme activity in the plasma [38]. Ophiobolin A can cause protein misfolding and the accumulation of misfolded proteins, leading to paraptosis-like cell death in glioblastoma cells ${ }^{[39]}$. Ophiobolin A displays different mechanisms of cell death in mammalian cells depending upon the cancer cell origin, and the mitochondria appear to be a central player in ophiobolin A-induced cancer cell death ${ }^{[40]}$. Ophiobolin A showed activity against cancer cell-lines A-549, HT-29, and Mel-20 at $\mathrm{IC}_{50}(50 \mathrm{ng} / \mathrm{mL})$ and cell-line P-388 at $\mathrm{IC}_{50}$ (25 ng/mL), also showed potent marginal activity against $P$. falciparum at $\mathrm{IC}_{50}(\mathrm{ng} / \mathrm{mL})$ <528.8 (D6 Clone, SI >2.1), 580 (W2 Clone, SI 1.9) in an antimalarial assay ${ }^{[41]}$. Ophiobolin A exhibited strong motility inhibition and viability reduction on boar spermatozoa and significantly damaged the sperm mitochondria at sublethal concentration by the dissipation of transmembrane potential in the mitochondrial inner membrane, also highly toxic to cell proliferation in MNA, FFL and PK-15 somatic cell lines under the level causing motility inhibition on boar spermatozoa ${ }^{[42]}$.

3-anhydro-6-hydroxy-ophiobolin A induced autophagy and promoted the degradation of $\alpha$-synuclein in PC12 cells, possessed strong autophagy-inducing activity to GFP-LC3 stable HeLa cells, also induce autophagy both in U2OS and SH-SY5Y cells ${ }^{[43]}$. Ophiobolin $\mathrm{O}$ reduced the viability of human breast cancer MCF-7 cells in a time-and dose-dependent manner and efficiently induced apoptosis In MCF-7 cells. In vivo, ophiobolin $\mathrm{O}$ suppressed tumor growth and showed little toxicity in mouse xenograft models ${ }^{[16,44]}$. Ophiobolin $\mathrm{H}$ induced hyperacusia in day-old chicks at rates up to $375 \mathrm{mg} \mathrm{kg}^{-1}$, but there was no mortality ${ }^{[12]}$. Ophiobolin P-T, 6-epi-21, 21-O-dihydroophiobolin G, 6-epi-ophiobolin $\mathrm{G}$ and 6-epi-ophiobolin $\mathrm{K}$ showed strong cytotoxicity against two cell lines including $K B$ and HepG2 cell line in comparison with the positive control etoposide. Ophiobolin T and 6-epi-ophiobolin G exhibited stronger cytotoxic activities against HepG2 than etoposide with $I C_{50}$ values of 0.24 and $0.37 \mu \mathrm{M}$, respectively ${ }^{[17]}$. Ophiobolins $B$ and $J$ showed phytotoxicity on various four weed species at the concentration of $0.5 \mathrm{mg} \mathrm{ml}^{-1}$, while ophiobolins $E$ and 8-epi-ophiobolins $\mathrm{J}$ appeared to be inactive ${ }^{[10]}$. Ophiobolin $U$ displayed $>75 \%$ lethality at $100 \mu \mathrm{g} \mathrm{mL}-1$ and LC $_{50}$ values of $48.1 \mu \mathrm{g} \mathrm{mL}^{-1}$ in the brine shrimp toxicity assay $^{[18]}$. Ophiobolin $\mathrm{K}$ showed cytotoxicity against tumor cell lines, including adriamycin -resistant mouse leukemia cells (P388), 
with $I_{50}$ of $0.27-0.65 \mu \mathrm{M}$. Especially, it showed seven times stronger cytotoxic activities against P388/ADR (adriamycin resistant cells) tumor cells than adriamycin [22].

2.2. Phytotoxicity. Ophiobolin A shows good stimulatory effect to $O$. aegyptiaca, $O$. cumana, and 0 . minor, these broomrapes were stimulated up to $50 \%$ in the concentration range of $10^{-4}-10^{-7} \mathrm{M}$ of $\mathrm{A}^{[45]}$. Ophiobolin A prevented cell proliferation even induced cell death in Nicotiana tabacum L. cv. Bright Yellow 2 (TBY-2) cells depending on the concentrations. In vitro growth-inhibitory assays on four cancer cell lines (A549, SKMEL28, Hs683 and B16F10), the mean $I_{50}$ growth inhibitory concentrations for 3-anhydro-6-epi-ophiobolin A were approximately 60 times higher than those for ophiobolin $A^{[20]}$. Ophiobolin A can mutate Lys-75, Lys-77, and Lys-148 residues in calmodulin molecule by site-directed mutagenesis, while Lys residues in positions 86 and/or 143 which are highly conserved in plant calmodulins did not react with ophiobolin $A^{[46]}$. Furthermore, kinetic analysis provide that lysine 75 in calmodulin is the primary inhibitory site for ophiobolin $A^{[47]}$.

Ophiobolin A inhibit spinach calmodulin, and the calmodulin may be one of the target proteins of the phytotoxic action of ophiobolin $A^{[48]}$. Ophiobolin $A$ inhibit the phosphorylation of $\mathrm{S} 6\left(\mathrm{IC}_{50}=1.9 \pm 0.2 \mu \mathrm{M}\right)$, ERK $\left(I C_{50}=0.28 \pm 0.02 \mu \mathrm{M}\right)$ and $\mathrm{RB}\left(\mathrm{IC}_{50}=\right.$ $1.42 \pm 0.1 \mu \mathrm{M})$, the effector proteins of $\mathrm{PI3K} / \mathrm{mTOR}$, Ras/Raf/ERK and CDK/RB pathways, respectively ${ }^{[31]}$. Ophiobolin $A$ could induce hyphal malformation in Phytophthora capsici, the effect may be due to the inhibition of $\beta-1,3$ glucan synthetase similarly ${ }^{[49]}$.

Ophiobolin B inhibited proton extrusion from maize coleoptiles by stimulating electrolites, glucose and aminoacid leakage. Moreover, ophiobolin B counteracts the biological activity of fusicoccin(FC), inhibits FC-proton extrusion, potassium uptake and cell enlargement ${ }^{[50]}$. Ophiobolin $G$ and ophiobolin $\mathrm{H}$ inhibited etiolated wheat coleoptile growth ${ }^{[12]}$. 6-epi-ophiobolin I, ophiobolin J, 8-deoxyophiobolin J, and ophiobolin I can cause yellowish to reddish lesions on rice cultivars in a nonselective manner at $10^{-4} \mathrm{M}$, also effectively reduce, by $50 \%$, dark $\mathrm{CO}_{2}$ fixation in rice leaf pieces in the range of $10^{-4}-10^{-5} \mathrm{M}^{[13]}$.

2.3. Antifungal and antimicrobial activities. Ophiobolins A and B showed antifungal activity on zygomycete with MIC values of

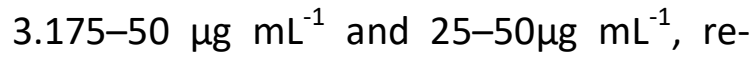
spectively. Ophiobolin A inhibited sporangiospore germination of mucor circinelloides and caused morphological changes [51]. The minimum inhibitory concentration of ophiobolin A against Candida albicans, Aspergillus flavus, Tricbopbyton mentagropbytes, Torulopsis cremoris, torulopsis petropbilum is $12.5,25,12.5,0.20$ and 1.56 $\mu \mathrm{M} \mathrm{ml}{ }^{-1}$, respectively ${ }^{[2,52]}$. 3-Anhydro-6hydroxy-ophiobolin A displays high efficacy against influenza $A$ virus infection in vitro and in vivo by inhibiting influenza virus replication and enhancing the host immunity $^{[53]}$.

Ophiobolin $\mathrm{P}$ and $\mathrm{T}$ showed moderate antibacterial activity against $B$. subtilis and meticillin-resistant $S$. aureus. Ophiobolin $T$ and 6-epi-ophiobolin $\mathrm{G}$ exhibited the cytotoxic activity against HepG 2 with $I_{50}$ of 0.24 and $0.37 \mu \mathrm{M}$, respectively ${ }^{[17]}$. Ophi- 
obolin $\mathrm{G}$ and ophiobolin $\mathrm{H}$ inhibited growth of Bacillus subtilis cultures, but ophiobolin $\mathrm{H}$ was a more potent inhibitor at rates above $250 \mu \mathrm{g} /$ disk than $\mathrm{G}^{[12]}$. Ophiobolin $\mathrm{U}$ and $(5 \alpha, 6 \alpha)$-ophiobolin $\mathrm{H}$ exhibited inhibitory activities against Escherichia coli with inhibitory diameters of 15 and $10 \mathrm{~mm}$, respectively, ophiobolin $U$ also showed activity against Staphylococcus aureus with inhibitory diameters of $10 \mathrm{~mm}$ at $30 \mu \mathrm{g} \mathrm{disk}{ }^{-1}$ [18].

Ophiobolin $\mathrm{K}$ showed high inhibitory activities against Aspergillus repens and Aspergillus glaucus with MIC value of $0.78 \mu \mathrm{g}$ $\mathrm{mL}^{-1}$, Alao exhibited potent activity against gram-positive bacteria (Bacillus subtilis, Staphylococcus aureus and Micrococcus luteus) with MIC values of $0.78,1.6$ and 3.1 $\mu \mathrm{g} \mathrm{\textrm {mL } ^ { - 1 }}{ }^{[54]}$. In comparison, tetracycline inhibits the growth of both gram-positive and gram-negative bacteria with MIC of 8 $\mu \mathrm{g} \mathrm{mL} \mathrm{L}^{-1[55]}$. At $75 \mu \mathrm{M}$, ophiobolin $\mathrm{K}$ exhibited 81.9, 84.5, and 79.9\% growth inhibition of C. acutatum, C. gloeosporioides and Fusarium oxysporum after $48 \mathrm{~h}$, respectively, and caused $86.9 \%$ growth inhibition of Phomopsis viticola after $120 \mathrm{~h}$. At $150 \mu \mathrm{M}$, 6 -epiophiobolin K showed $96 \%$ growth inhibition of $P$. obscurans after $120 \mathrm{~h}^{[14]}$.
2.4. Activities of ophiobolins and 6-epi ophiobolins. While summarizing the bioactivities of ophiobolins, a conclusion can be obtained. The activities of ophiobolins with $\beta$-stereochemistry at C-6 position were generally higher than $\alpha$-stereochemistry, some of them even showed big difference.

In the potency of inhibiting maize calmodulin in vitro and the effects on excised roots assay, ophiobolin $A$ is better than 6-epi-ophiobolin $A^{[56]}$. In the leaf puncture assay to several monocotyledons and dicotyledons, ophiobolin $A$ is more active in comparison with 6-epi-ophiobolin $A^{[57]}$. Ophiobolin $\mathrm{K}$ and 6-epi-ophiobolin $\mathrm{K}$ showed trypanocidal activities with $\mathrm{IC}_{50}$ values of 13.0 and $9.62 \mu \mathrm{M}$ against $T$. cruzi, this is approximately four and two times higher in comparison with the drug control benznidazole $(3.84 \mu \mathrm{M})^{[14,58]}$.

In the nematocidal activity in a $C$. elegans motility assay, ophiobolin $C$ shows the most active with an $L_{50}$ value of $5 \mu \mathrm{M}$, ophiobolin $\mathrm{M}$ and ophiobolin $\mathrm{K}$ were similarly active with $\mathrm{LD}_{50}$ values of 13 and

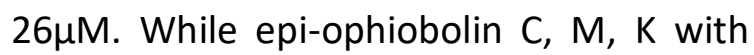
$L D_{50}$ values of 130,130 and more than $260 \mu \mathrm{M}$, respectively (Table 1$)^{[2,15,59]}$.

Table 1. Inhibition of $\left[{ }^{3} \mathrm{H}\right]$ ivermectin binding and biological potencies on $\mathrm{C}$. elegans motility in vivo for ophiobolins.

\begin{tabular}{|c|c|c|c|}
\hline Number & Compound & Binding $\left(K_{\mathrm{i}} \mu \mathrm{M}\right)$ & Motility $\left(\mathrm{LD}_{50} \mu \mathrm{M}\right)$ \\
\hline 1 & Ophiobolin M & 31 & 13 \\
\hline 2 & Epi-ophiobolin M & 156 & 130 \\
\hline 3 & Ophiobolin C & 15 & 5 \\
\hline 4 & Epi-ophiobolin C & 180 & 130 \\
\hline 5 & Ophiobolin K & 130 & 26 \\
\hline 6 & Epi-ophiobolin K & 260 & $>260$ \\
\hline 7 & Dihydroophiobolin C & 45 & 25 \\
\hline
\end{tabular}


In the cytotoxic activity assay towards CLL cells, ophiobolin $A, B, C$, and $K$ showed the strongest effects with $\mathrm{LC}_{50}$ values between 1 and $8 \mathrm{nM}$, while some derivatives were inactive, ophiobolin $\mathrm{K}$ and 6-epiophiobolin $\mathrm{K}$ showed effects with $\mathrm{LC}_{50}$ of $4 \mathrm{nM}$ and Inactive (Table 2$)^{[3]}$.

Table 2. Apoptosis inducing activity of the ophiobolins towards CLL cells.

\begin{tabular}{|c|c|}
\hline Compound & LC $_{50}(\mathrm{nM})$ \\
\hline Ophiobolin A & $1 \mathrm{nM}$ \\
\hline 3-anhydro-ophiobolin A & Inactive \\
\hline 3-anhydro-6-epi-ophiobolin A & Inactive \\
\hline Ophiobolin B & $2 \mathrm{nM}$ \\
\hline Ophiobolin C & $8 \mathrm{nM}$ \\
\hline 6-epiophiobolin G & Inactive \\
\hline Ophiobolin H & Inactive \\
\hline Ophiobolin $\mathrm{K}$ & $4 \mathrm{nM}$ \\
\hline 6-epiophiobolin $\mathrm{K}$ & Inactive \\
\hline 6-epiophiobolin $\mathrm{H}$ & Inactive \\
\hline
\end{tabular}

In the antifungal and antimicrobial activities assay, ophiobolin $L$ showed better activity than 6-epi-ophiobolin $L$ against most of fungi except for the Staphylococcus aureus ${ }^{[46]}$. Ophiobolin $\mathrm{K}$ displayed an $\mathrm{IC}_{50}$ of $0.51 \mu \mathrm{M}$ and 6-epi-ophiobolin an $\mathrm{IC}_{50}$ of $2.97 \mu \mathrm{M}$ against the both tumoral cells TK-10 and MCF-7, respectively ${ }^{[14]}$.

The anti-biofilm activity of ophiobolin $\mathrm{K}$ and 6-epi-ophiobolin $\mathrm{K}$ were 4.1 and $65 \mu \mathrm{M}$, respectively, also ophiobolin $\mathrm{K}$ showed antibiotic activity to mycobacterium smegmatis and mycobacterium bovis of 8.2 and 64 $\mu \mathrm{M}$, respectively, but 6-epi-ophiobolin $\mathrm{K}$ was inactive ${ }^{[60-61]}$.

3-anhydro-6-hydroxy-ophiobolin A(1) exhibited potent antiproliferative activity against cell lines HepG2 and $\mathrm{K} 562$ with $\mathrm{IC}_{50}$ of $6.49 \mu \mathrm{M}$ and $4.06 \mu \mathrm{M}$, respectively, while 3-anhydro-6-epi-ophiobolin $A(3)$ showed weak activity with $\mathrm{IC}_{50}$ of $47.1 \mu \mathrm{M}, 35.6 \mu \mathrm{M}$, respectively. Also $A(1)$ presented moderate antifungal activity against Candida albicans and strong antimicrobial activity against Bacille Calmette-Guerin, Bacillus subtilis, Staphylococcus aureus, while A(3) showed weak activity in these assays with MIC value larger than $100 \mathrm{\mu g} \mathrm{mL}^{-1}$ (Table 3) ${ }^{[62]}$.

Table 3. Cytotoxicity and antimicrobial activity of compounds 1, 2, 3.

\begin{tabular}{|c|c|c|c|c|c|c|c|c|}
\hline \multirow{2}{*}{ Compounds } & \multicolumn{9}{|c|}{ MIC $(\mu \mathrm{g} / \mathrm{mL})$} & \multicolumn{2}{c|}{$\mathrm{IC}_{50}(\mu \mathrm{M})$} \\
\cline { 2 - 9 } & BCG & BS & PA & SA & MRSA & CA & HepG 2 & K562 \\
\hline 1 & 12.5 & 12.5 & $>100$ & 12.5 & 12.5 & 50 & $6.49 \pm 0.34$ & $4.06 \pm 0.50$ \\
\hline 2 & $>100$ & $>100$ & $>100$ & $>100$ & $>100$ & $>100$ & $55.7 \pm 3.8$ & $39.5 \pm 5.5$ \\
\hline 3 & $>100$ & $>100$ & $>100$ & $>100$ & $>100$ & $>100$ & $47.1 \pm 4.8$ & $35.6 \pm 4.4$ \\
\hline $\begin{array}{c}\text { Positive } \\
\text { control }\end{array}$ & isoniazid & vancomycin & ciprofloxacin & vancomycin & vancomycin & ketoconazole & Etoposide & \\
\cline { 2 - 7 } & 0.05 & 0.50 & 1.00 & 1.00 & 1.00 & 0.02 & $6.41 \pm 0.50$ & \\
\hline
\end{tabular}




\section{Views of structure-bioactivity relation- ship}

\subsection{Functional group}

Some studies showed, functional group causes the different activity of ophiobolins

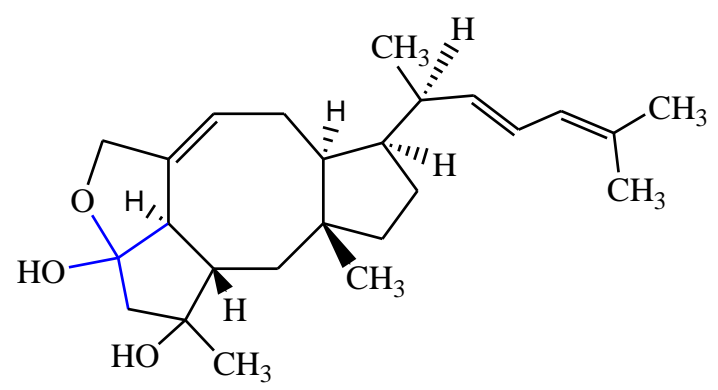

Ophiobolin H and derivatives, such the hemiacetal structure in ophiobolin $\mathrm{H}$ is more inhibitory than the ketoaldehyde structure in ophiobolin $\mathrm{G}$ in inhibiting the growth of wheat coleoptiles (Fig. 1) ${ }^{[2,12]}$.

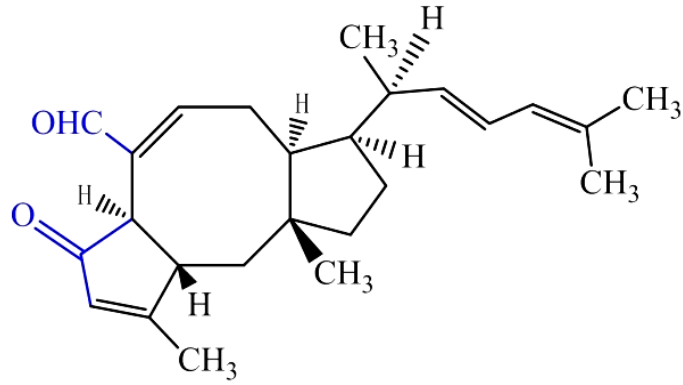

Ophiobolin G

Fig. 1. Structure of Ophiobolin H and G.

In the antibacterial activity assay of ophiobolins and derivatives, ophiobolin $T$ showed stronger in both cytotoxic and antibacterial activities, while others compounds showed bioactivities only in part
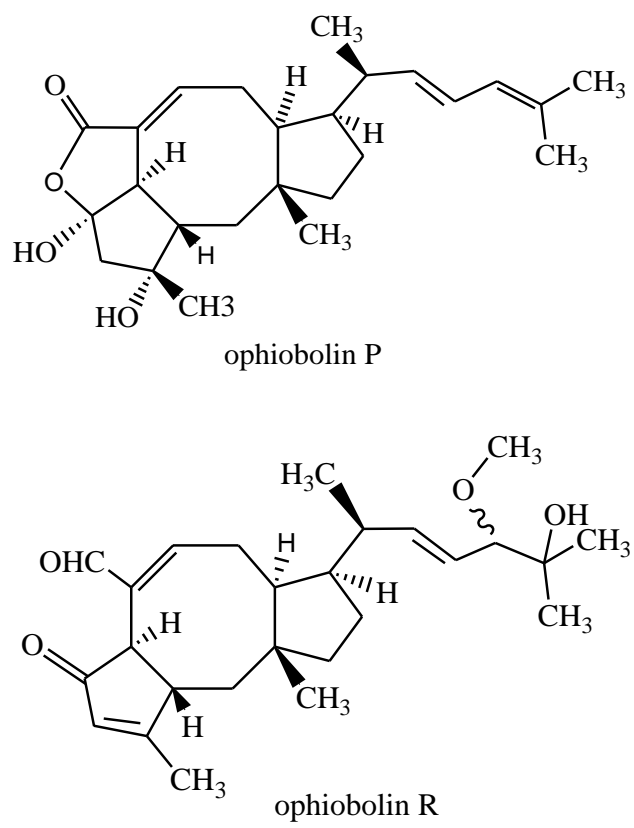

cell lines, which suggests that the furan ring formed in the side-chain at C-15 significantly influences the bioactivities (Fig. 2) [17].
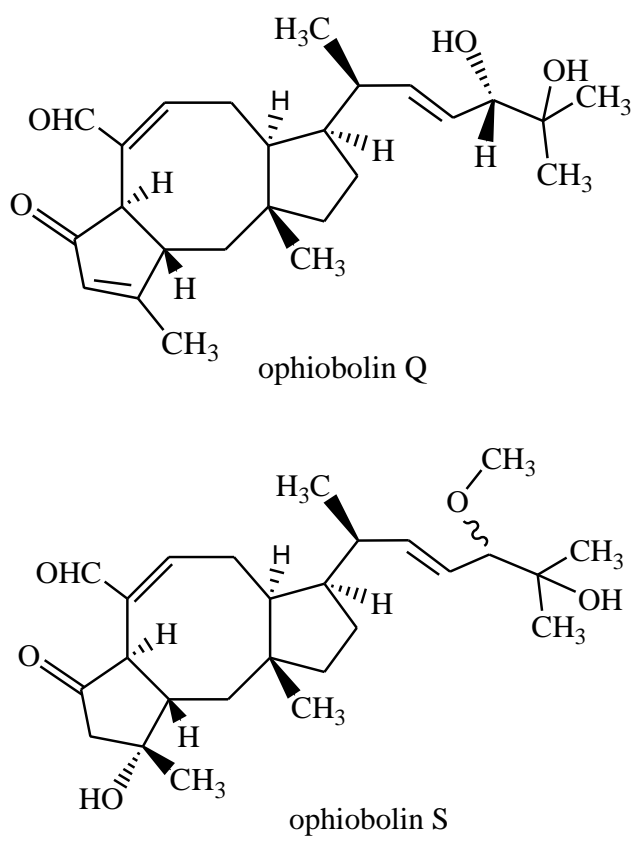

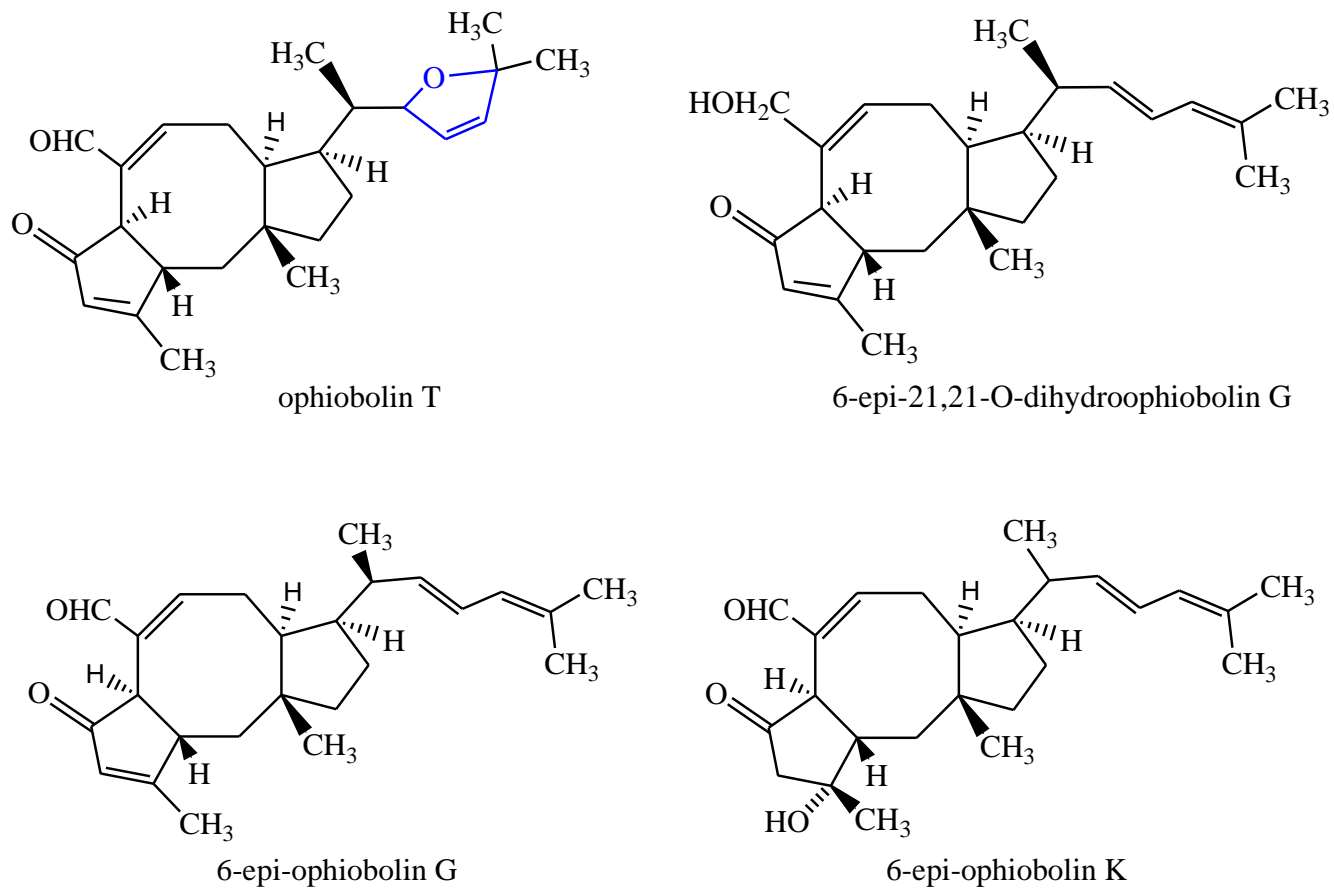

Fig. 2. Structures of ophiobolins and derivatives, ophiobolin T with furan ring.

According to bioactivity assays (Table 3), 3-anhydro-6-hydroxy-ophiobolin showed better activity than 3-anhydroophiobolin $A(2)$ and 3-anhydro-6-epiophiobolin $A(3)$, it was considered the in- troduction of a hydroxyl group at C-6 in 3-anhydro-6-hydroxy- ophiobolin A resulted in the great enhancement of anti-microbial and anti-tumor activity assays (Fig. 3) ${ }^{[62]}$.
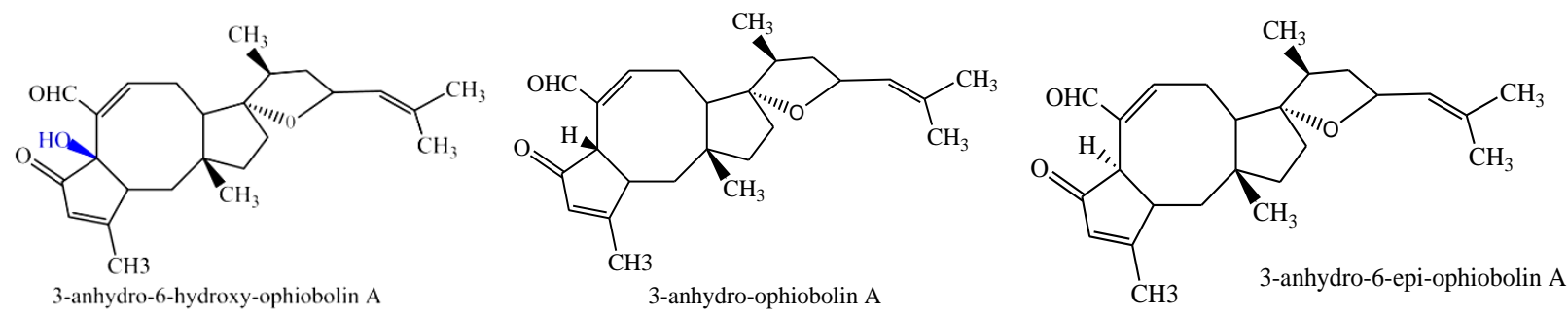

Fig. 3. Structures of compounds in Table 3, ophiobolin with hydroxyl group at C-6.

In the activity assay of three compounds and etoposide against five human tumor cell lines, 6-epi-ophiobolin A, 3-anhydro-6epi-ophiobolin A exhibited significant cytotoxic activity, have $\mathrm{IC}_{50}$ values in the range of $1 \mu \mathrm{g} / \mathrm{ml}$, while ophiobolin I was less active with $\mathrm{IC}_{50}$ values more than $10 \mu \mathrm{g} / \mathrm{ml}$, since the first two compounds have no significant difference in the activity, the 3-OH of 6-epi-ophiobolin A seemed to have little effect on the cytotoxic (Fig. 4) [63]. 

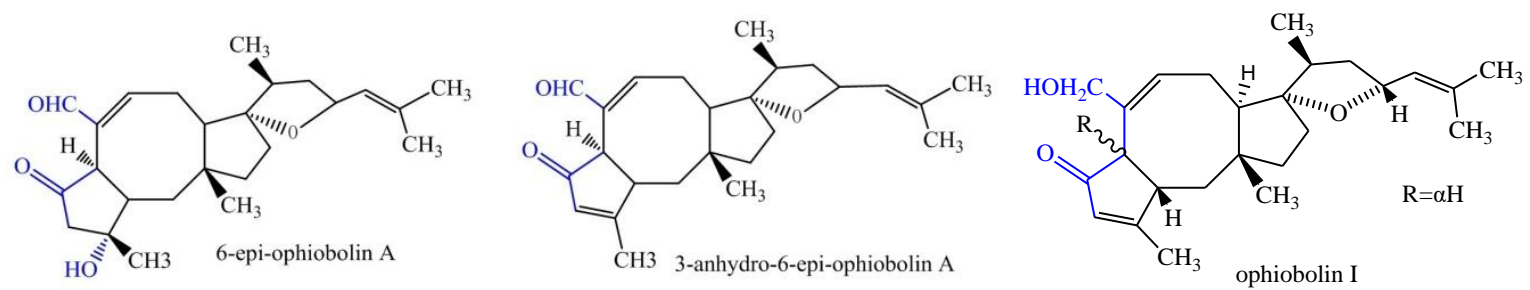

Fig. 4 Structures of three compounds.

Indeed, according to convert ophiobolin A to its analogs under different conditions and compare their anticancer activities to cell lines, these data shows that the $\mathrm{C5}$, C21-dicarbonyl functionality as critical for anticancer activity in this family of natural products. In addition, change or elimina- tion the C5, C21-dicarbonyl functionality result in a significant drop in activity, such as 21,21-O-dihydroophiobolin $A^{[62]}$ and ophiobolin I (Fig. 4) [63], In contrast, changes in the C15-C25 fragment, such as ophiobolin K, are tolerated (Fig. 5) ${ }^{[22,64]}$.
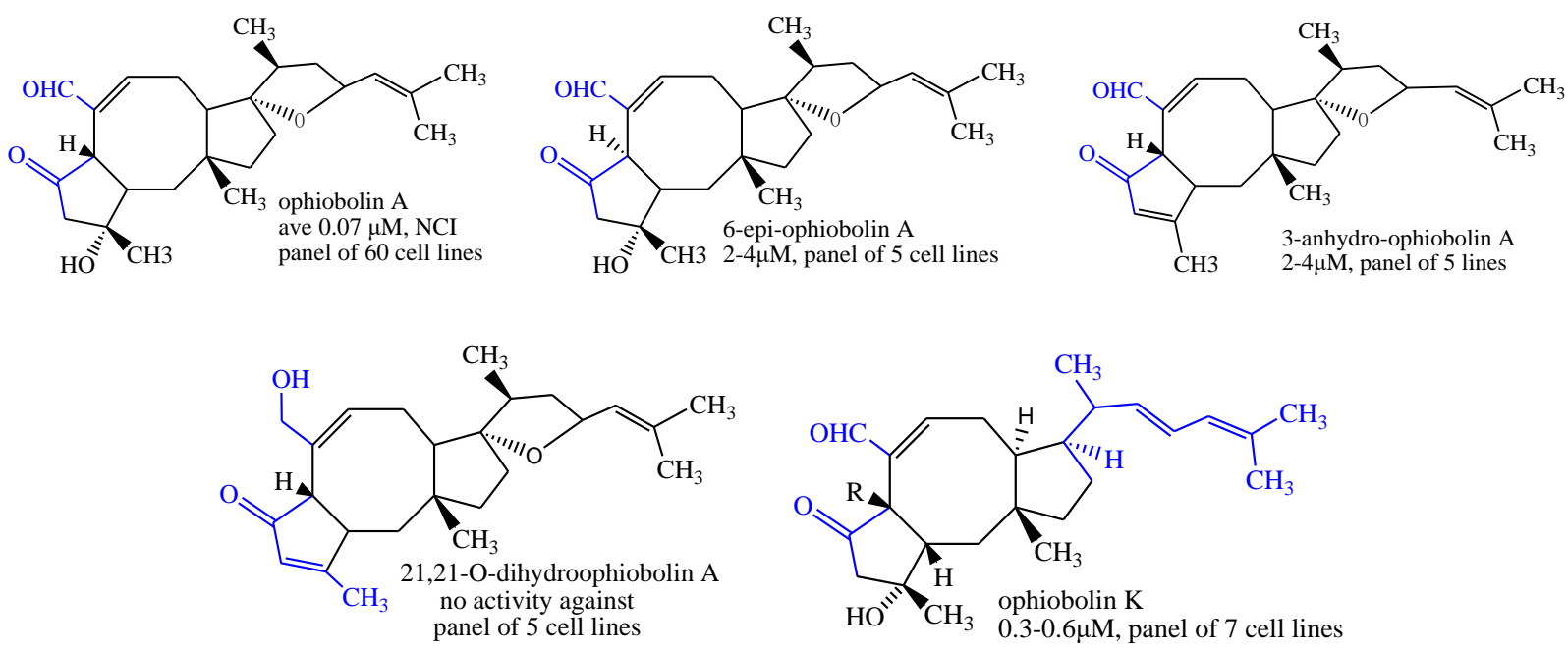

Fig. 5. Ophiobolin A and analogs. C5, C21-dicarbonyl and C15-C25 fragment.

Also compounds incorporating modifications of the $\mathrm{C} 18, \mathrm{C} 19$-alkene, have retained a significant portion of the antiproliferative potency, so the $\mathrm{C} 15-\mathrm{C} 25$ fragment and $\mathrm{C} 18$, C19-alkene, have little to do with their activities $^{[64-65]}$.

Assayed on punctured detached leaves of several grass and dicotyledon weeds of ophiobolin A, 6-epi-Ophiobolin A, 3-anhydro-6-epi-ophiobolin $A$ and ophiobolin I, ophiobolin A proved to be on average more phytotoxic as compared to the other related compounds, some structural features appear to be important for the phytoxicity, such as the hydroxy group at $\mathrm{C}-3$, the stereochemistry at $\mathrm{C}-6$, and the aldehyde group at C-7 (Fig. 6) ${ }^{[57]}$. 

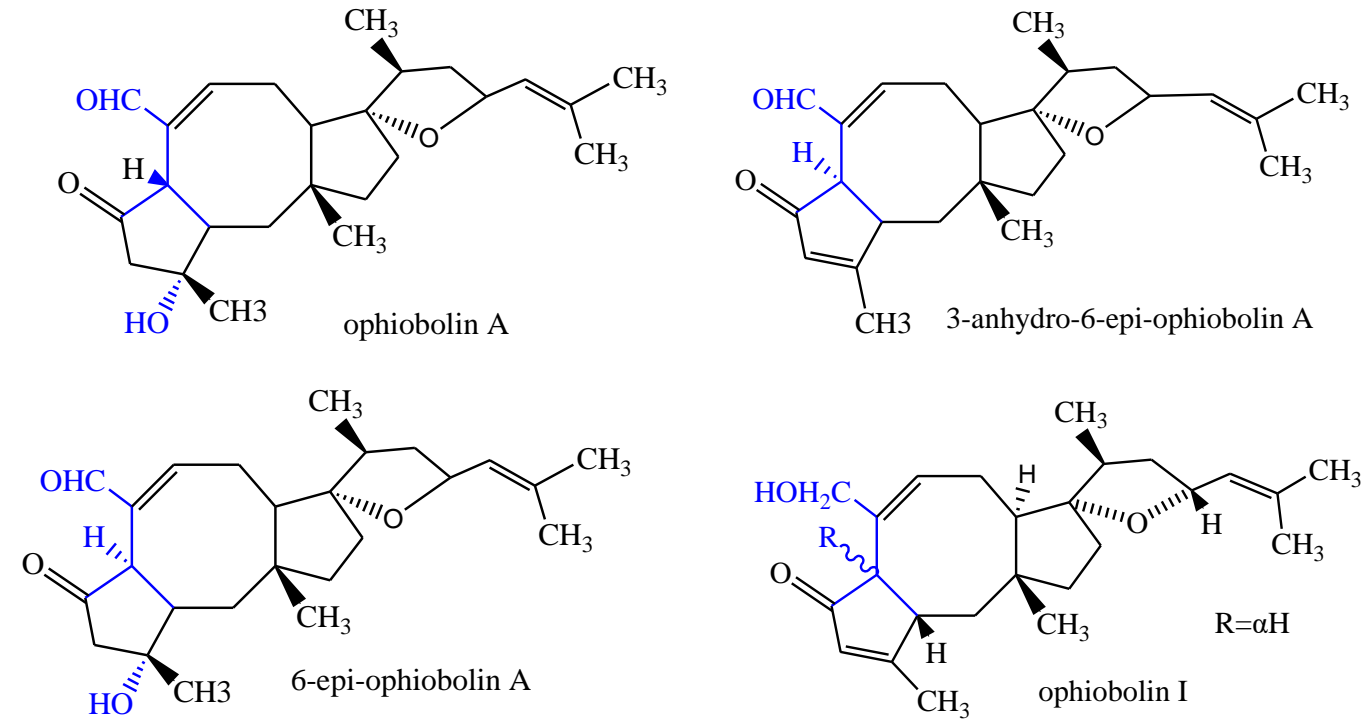

Fig. 6. Structural features appear to be important for the phytoxicity.

Dereplication of some ophiobolin derivatives possessing different activity in combination with structural analysis allowed a correlation of the chemical structure and conformation with the extent of bioactivity, identifying the hydroxy group at $\mathrm{C} 3$ and an aldehyde at C21, as well as the A/B-cis ring structure, as indispensible for the strong activity of the ophiobolins ${ }^{[3]}$.

\subsection{Configuration}

Some literatures suggest configuration is
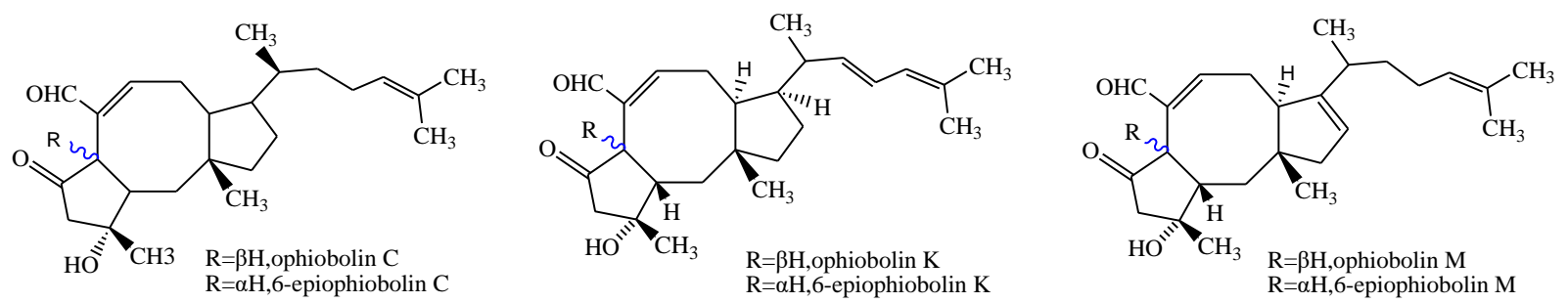

Fig. 7. Structures of compounds, ophiobolin with $\alpha$ and $\beta$-hydrogen.

\subsection{The tricyclic 5-8-5 ring structure}

As mentioned above, many ophiobolin family members have good bioactivities, the cause of different activities of ophiobolin. According to compare three pairs of natural ophiobolin analogues for nematocidal activity in a $C$. elegans mobility assay (Table 1) $^{[15]}$, stereoisomers with hydrogen at $\mathrm{C}-6$ position in either $\beta$ - (ophiobolin $\mathrm{M}$, ophiobolin $C$ and ophiobolin K) or $\alpha$ (6-epiophiobolin M, 6-epiophiobolin C and 6-epiophiobolin K), in each case, ophiobolins with $\beta$-stereochemistry were found to be more potent (Fig. 7). 
terpene skeleton usually show different activities, some of them are even less active, which suggest unique molecular structures is not the main factor of activity.

In the cytotoxicity against murine L5178Y lymphoma cells, five ophiobolin-type sesterterpenoids were tested at a concentration of $10 \mu \mathrm{g} / \mathrm{ml}$, As a result, none of the compounds reduced survival of cells by more than $10 \%-20 \%$ compared to control, this suggest that molecular structure may not the main factor of ophiobolin activity ( Fig. 8) ${ }^{[66-67]}$.

In the determination of capacity to stimulate the seed germination of several orobanche species, ophiobolin A and several fusicoccin derivatives which have the similar sesterterpene structure were tested in the concentration range of $10^{-4}-10^{-7} \mathrm{M}$. The results obtained showed that ophiobolin $A(9)$, and the hexacetyl and pentacetyl isomers of $16-O$-demethyl-de-tert-Pentenyl-fusicoccin $(7,8)$ prepared by chemical modification of the fusicoccin show the highest stimulatory effect, while the fusi$\operatorname{coccin}(1)$ and other fusicoccin derivatives(2-6) appeared to be practically inactive (Fig. 9) ${ }^{[45,68]}$. As shown in figure 9, with the same 5-8-5 ring system, compound 1-4 had the low stimulatory effect, while compound 7-8 and ophiobolin A showed the highest stimulatory effect. In addition, compound 5-6, which had the tricyclic 6-8-5 ring, also showed low stimulatory effect like compound 1-4. On this basis, it can be inferred there is no special relationship between bioactivity and the tricyclic 5-8-5 ring structure.
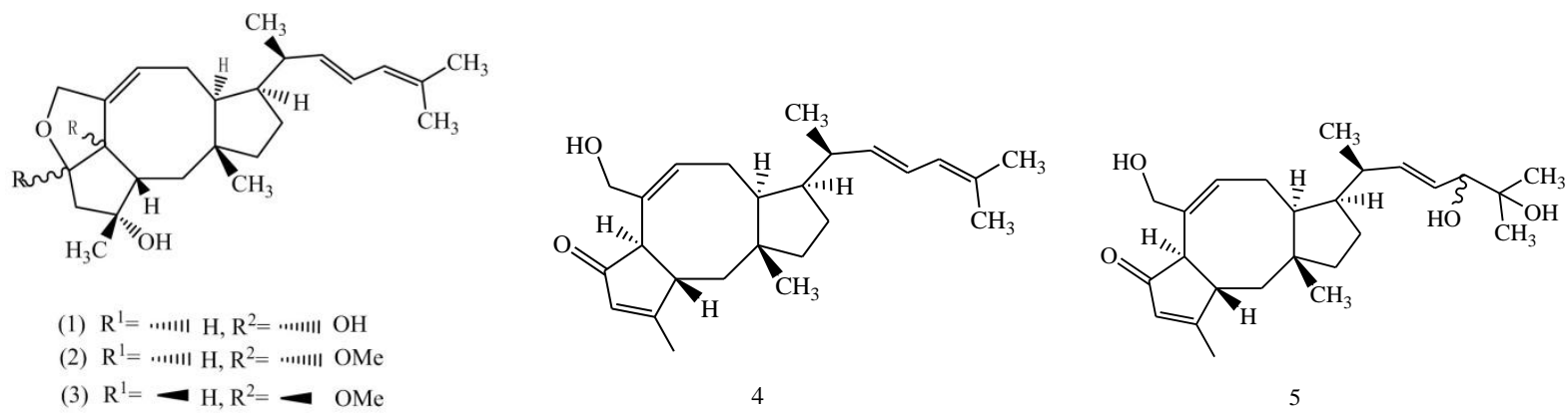

Fig. 8. Five ophiobolin-type sesterterpenoids
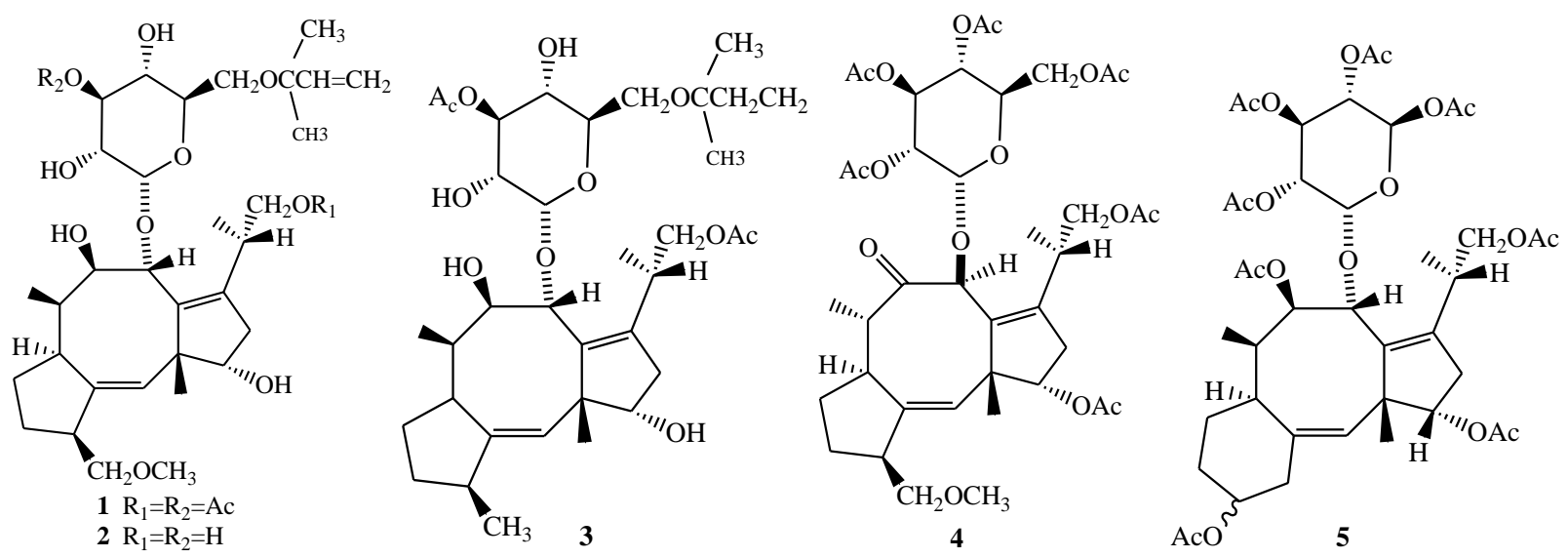

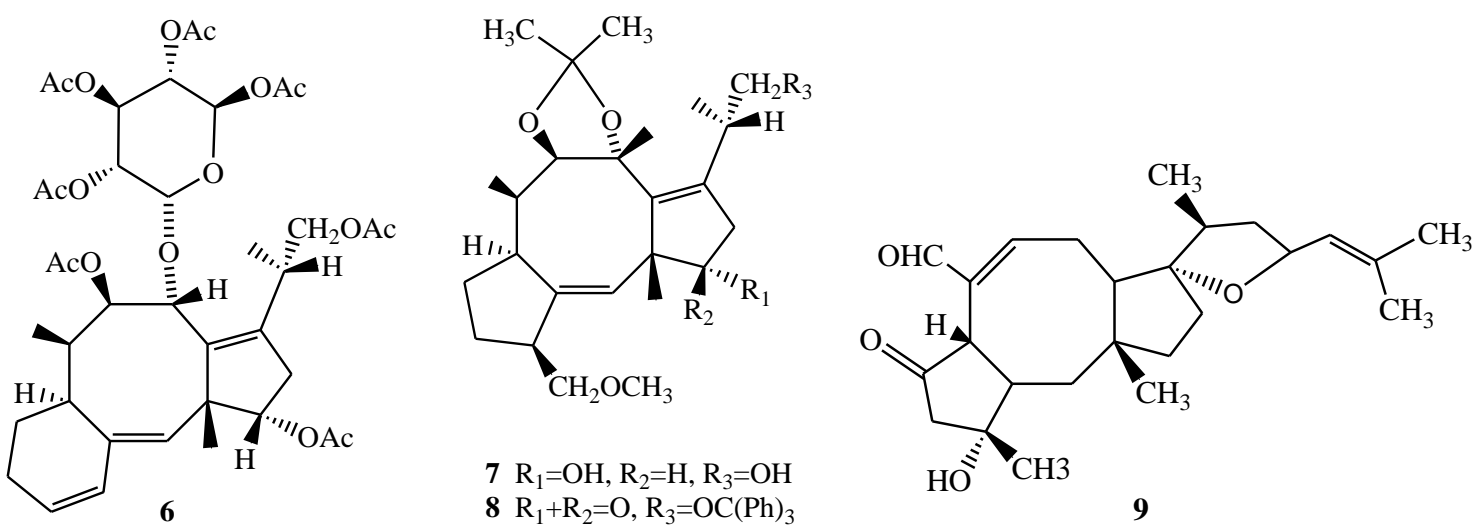

Fig. 9. Structures of fusicoccin(1), some of its dirivatives(2-6), fussicoccin deacetyl aglycone derivatives(7-8), ophiobolin $A(9)$.

As mentioned above, there is no special relationship between bioactivity and the tricyclic 5-8-5 ring structure, so the functional group and configuration may the causes of different activities of ophiobolin. As shown in Fig 10, ophiobolin and 6-epi-ophiobolin of each group (mentioned in Part 2.4) have the same planar
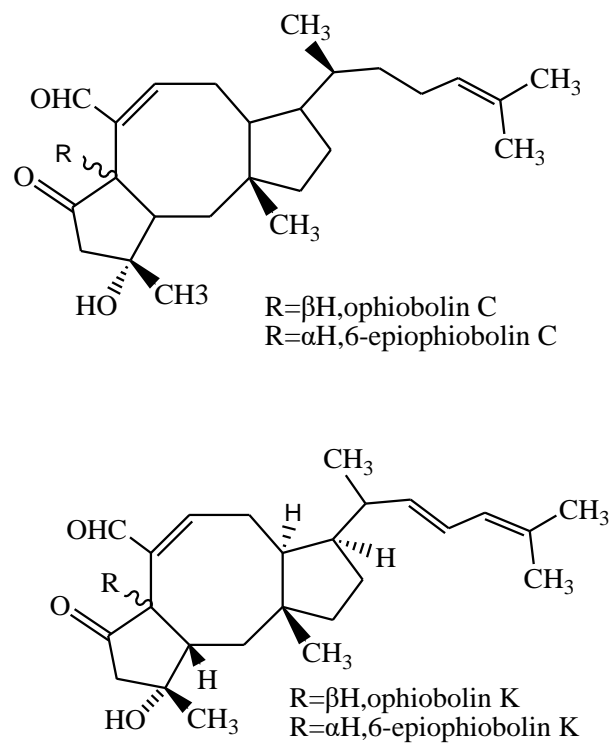

structures and functional groups, so the different configuration connected to C-6 may the causes of different activities. Therefore, we mainly studied whether there were other factors that caused the activity difference of ophiobolin and 6-epi-ophiobolin.
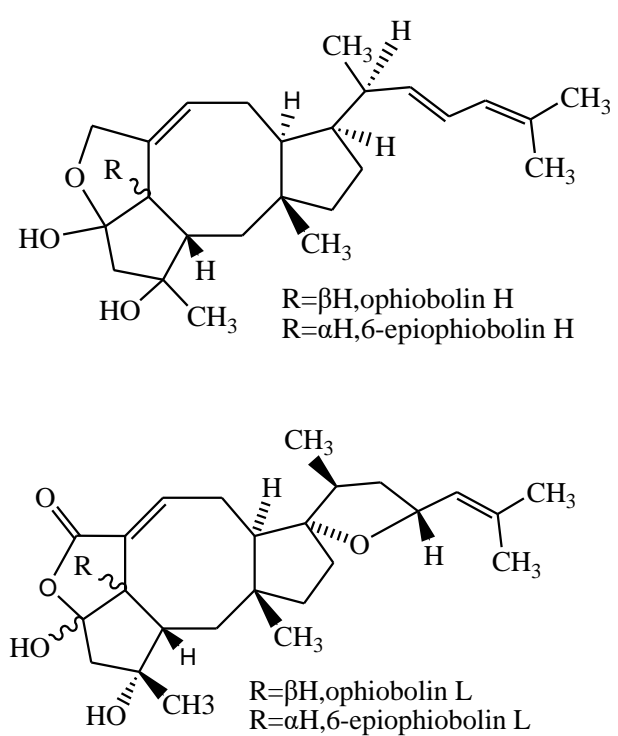

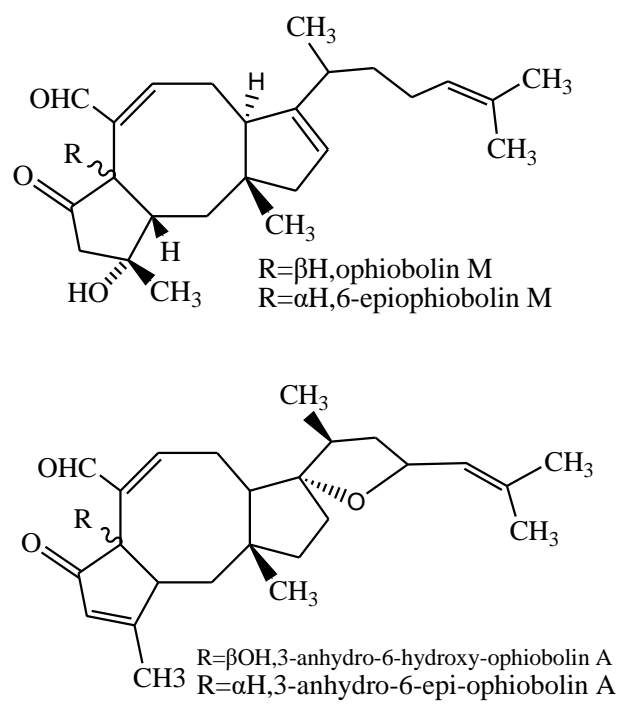
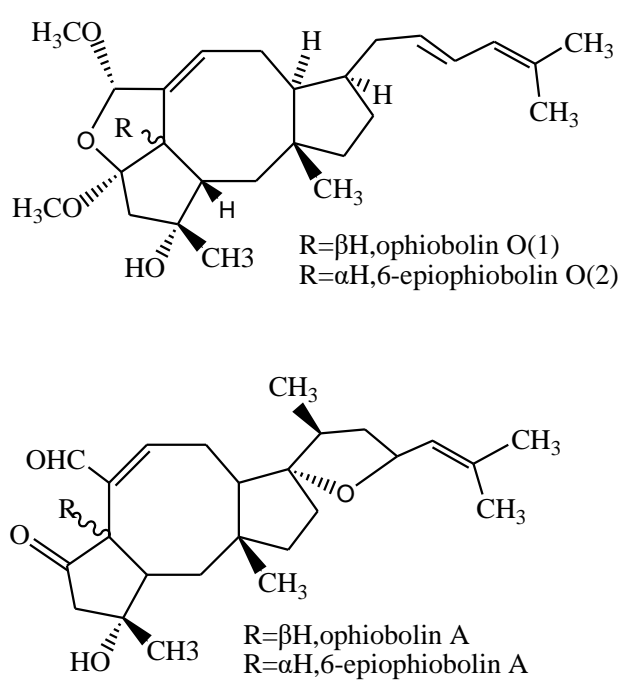

Fig. 10. Structures of compounds of each group in Table 4

\section{Structure-bioactivity relationship of ophiobolins and 6-epi ophiobolins}

According to our study, we chose Ophiobolin $\mathrm{O}(1), \mathrm{K}(3)$ and 6-epi-ophiobolin $\mathrm{O}(2), \mathrm{K}$ (4) as objects which were isolated from one endophytic fungus-Aspergillus $s p^{[69]}$, the molecular formulas were suggested as $\mathrm{C}_{27} \mathrm{H}_{42} \mathrm{O}_{4}$ and $\mathrm{C}_{25} \mathrm{H}_{36} \mathrm{O}_{3}$ using HRFABMS and 13C NMR. (1) and (2), (3) and (4) were identical with the same planar structures and functional groups, while the bioactivity of them to mouse leukemia cell line (P388) also followed this role, showed

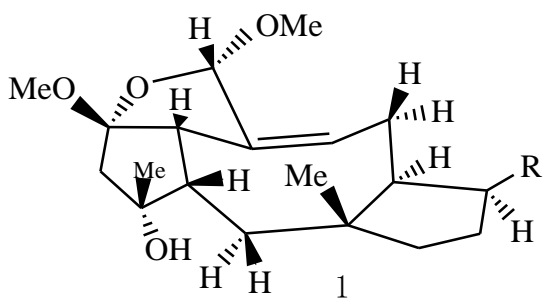

bioactivity to mouse leukemia cell line (P388) with MIC values of 4.7, 9.3, 13.3 and $24.9 \mu \mathrm{M}$, respectively, which indicated that there should have a difference. $1 \mathrm{H}$ and $13 \mathrm{C}$ NMR spectra of them were analyzed in detail, as well as the 2-D spectra of COSY, TOCSY, HMBC and HSQC. During the absolute configuration elucidation, a big difference was found in the position C-7 and the hydrogen atom configuration connected to $\mathrm{C}-6$. The hydrogen atom connected to $C-6$ in (1) was in $\beta$ side, but in (2) was $\alpha$ side. In the study of (3) and (4), it showed same result (Fig. 11).

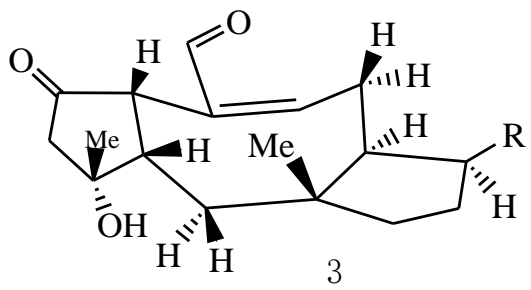



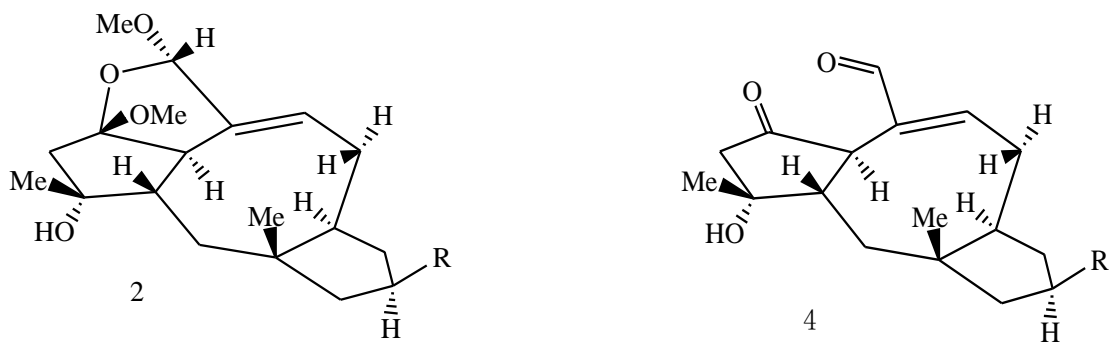

Fig. 11. The stereochemistry of ophiobolins and 6-epi-ophiobolin

Since the configuration connected to C-6 has been mentioned as the causes of different activities, we mainly studied the structures of $\mathrm{C}-7$, including the calculation of bond lengths, bond orders and the molecular energy, the steric difference of the isomers was also discussed as well as the impact on the biological activity.

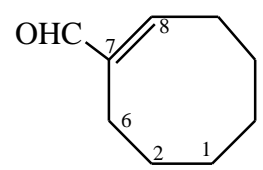

Structures in C-7(1)
Coincidentally, these eight pairs of compounds in Fig. 10 can be divided into two parts according to the structure at $\mathrm{C}-7$, one part were $A, \quad C, K, \quad M$ and 3-anhydro-6-hydroxy-ophiobolin $A$, the other were $\mathrm{L}, \mathrm{O}$ and $\mathrm{H}$ (Fig. 12). So, the ophiobolin $\mathrm{O}$ and $\mathrm{K}$ which could cover these two structures and had good representativeness.

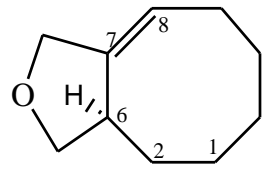

Structures in C-7(2)

Fig. 12. Compounds with different structures in C-7

\subsection{Theoretical study details}

The theoretical calculations were carried out by using density functional theory (DFT) method implemented in the Gaussian 09 program ${ }^{[70]}$, and the hybrid exchange correlation functional B3LYP ${ }^{[71-72]}$ was employed. For $\mathrm{C}, \mathrm{H}$ and $\mathrm{O}$, all electrons were explicitly considered within the $6-31+G(d$, p) basis set. All the geometrical structures were fully optimized, and vibrational frequency analyses were calculated to confirm that they are stable minima on the potential energy surface. Natural popula- tion analyses (NPA) were carried out using the natural bond orbital (NBO) method ${ }^{\text {[73] }}$ implemented in NBO 5.0 program ${ }^{[74]}$. By frequency analysis, all optimized geometries had no imaginary frequency and correspond to the lowest point of the reaction potential energy surface. In order to distinguish all atoms, all the related atoms were noted (Fig. 13). Through the optimization results, the stable configurations energy was accessed. All the optimized geometries bond length and bond order were listed (Table 4, 5). 

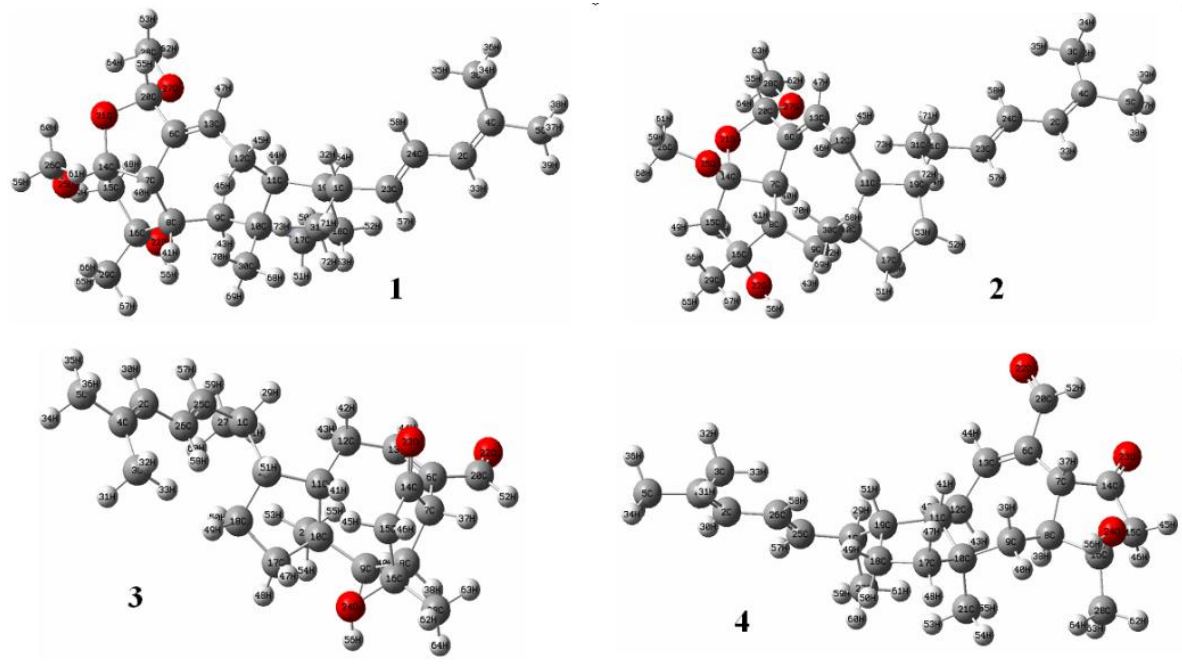

Fig. 13. Optimized structures of compounds 1-4

Table 4. The calculation of bond length and bond order of compound 1 and 2 .

\begin{tabular}{|c|c|c|c|c|c|c|c|c|c|}
\hline \multirow{2}{*}{ Position } & \multicolumn{2}{|c|}{ BondLength /nm } & \multicolumn{2}{|c|}{ Bond order } & \multirow{2}{*}{ Position } & \multicolumn{2}{|c|}{ Bond Length /nm } & \multicolumn{2}{|c|}{ Bond order } \\
\hline & 1 & 2 & 1 & 2 & & 1 & 2 & 1 & 2 \\
\hline \multirow{2}{*}{$\mathrm{C}(7)-\mathrm{H}(40)$} & 0.109 & 0.110 & 0.881 & 0.852 & \multirow{2}{*}{$\mathrm{C}(15)-\mathrm{H}(49)$} & \multirow{2}{*}{0.1092} & \multirow{2}{*}{0.1093} & \multirow{2}{*}{0.8998} & \multirow{2}{*}{0.9101} \\
\hline & 7 & 4 & 0 & 5 & & & & & \\
\hline \multirow{2}{*}{$\mathrm{C}(6)-\mathrm{C}(7)$} & 0.151 & 0.150 & 0.994 & 0.991 & \multirow{2}{*}{$C(16)-C(29)$} & \multirow{2}{*}{0.1536} & \multirow{2}{*}{0.1530} & \multirow{2}{*}{1.0095} & \multirow{2}{*}{1.0149} \\
\hline & 9 & 2 & 2 & 2 & & & & & \\
\hline \multirow{2}{*}{$\mathrm{C}(6)-\mathrm{C}(13)$} & 0.133 & 0.133 & 1.871 & 1.876 & \multirow{2}{*}{$\mathrm{C}(16)-\mathrm{O}(22)$} & \multirow{2}{*}{0.1464} & \multirow{2}{*}{0.1471} & \multirow{2}{*}{0.9066} & \multirow{2}{*}{0.9041} \\
\hline & 8 & 4 & 4 & 4 & & & & & \\
\hline \multirow{2}{*}{$\mathrm{C}(13)-\mathrm{C}(12)$} & 0.150 & 0.151 & 1.022 & 1.022 & \multirow{2}{*}{$\mathrm{C}(14)-\mathrm{O}(21)$} & \multirow{2}{*}{0.1468} & \multirow{2}{*}{0.1440} & \multirow{2}{*}{0.8724} & \multirow{2}{*}{0.9217} \\
\hline & 9 & 6 & 1 & 3 & & & & & \\
\hline \multirow{2}{*}{$\mathrm{C}(12)-\mathrm{C}(11)$} & 0.155 & 0.156 & 0.981 & 0.991 & \multirow{2}{*}{$\mathrm{C}(20)-\mathrm{O}(21)$} & 0.1446 & 0.400 & - & 0067 \\
\hline & 6 & 1 & 2 & 7 & & 0.1440 & 0.1490 & 0.9012 & 0.0002 \\
\hline$C$ (11) $C(10)$ & 0.157 & 0.158 & 0.970 & 0.968 & $C(0)$ & 01512 & 01520 & 00000 & 00067 \\
\hline$C(11)$ & 1 & 4 & 1 & 5 & 40 & 0.1512 & 0.1520 & 0.9900 & 0.9001 \\
\hline$C(10)$ & 0.156 & 0.155 & 0.984 & 0.986 & 77) & 0.147 & 0 & 00025 & ( \\
\hline$C(10)-C(y)$ & 6 & 6 & 2 & 7 & $C(20)-U(2 l)$ & 0.1443 & 0.1420 & 0.9035 & 0.9589 \\
\hline$C$ & 0.154 & 0.153 & 1.005 & 1.001 & 7) & 0 & 01 & 00704 & 00702 \\
\hline (0) & 6 & 5 & 8 & 7 & $4(10)-C(1 /)$ & 0.1500 & 0.1500 & 0.9184 & 0.9183 \\
\hline$C(s)$ & 0.158 & 0.153 & 0.964 & 0.982 & ) & 01 & 0 & $10+2$ & 06 \\
\hline$c(0)-C(1)$ & 3 & 0 & 4 & 4 & $C(1 /)-C(18)$ & 0.1545 & 0.1534 & 1.0092 & 1.0100 \\
\hline$C(0))$ & 0.109 & 0.109 & 0.904 & 0.882 & $C$ & 01562 & 01554 & 00008 & 00040 \\
\hline$-(0)-11(41)$ & 4 & 4 & 3 & 0 & $4(18)-(19)$ & 0.1503 & 0.1554 & 0.9908 & 0.9949 \\
\hline$\Omega$ & 0.109 & 0.109 & 0.907 & 0.910 & 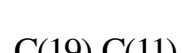 & 01585 & 05 & 0763 & 3 \\
\hline & 1 & 1 & 8 & 5 & & & & & \\
\hline
\end{tabular}




\begin{tabular}{|c|c|c|c|c|c|c|c|c|c|}
\hline $\mathrm{C}(12)-\mathrm{H}(45)$ & $\begin{array}{c}0.109 \\
6\end{array}$ & $\begin{array}{c}0.109 \\
8\end{array}$ & $\begin{array}{c}0.908 \\
5\end{array}$ & $\begin{array}{c}0.910 \\
5\end{array}$ & $\mathrm{C}(19)-\mathrm{C}(1)$ & 0.1565 & 0.1565 & 0.9784 & 0.9792 \\
\hline $\mathrm{C}(12)-\mathrm{H}(46)$ & $\begin{array}{c}0.109 \\
7\end{array}$ & $\begin{array}{c}0.109 \\
8\end{array}$ & $\begin{array}{c}0.906 \\
3\end{array}$ & $\begin{array}{c}0.892 \\
7\end{array}$ & $\mathrm{C}(17)-\mathrm{H}(50)$ & 0.1099 & 0.1100 & 0.9134 & 0.9142 \\
\hline $\mathrm{C}(11)-\mathrm{H}(44)$ & $\begin{array}{c}0.109 \\
9\end{array}$ & $\begin{array}{c}0.109 \\
8\end{array}$ & $\begin{array}{c}0.894 \\
9\end{array}$ & $\begin{array}{c}0.901 \\
2\end{array}$ & $\mathrm{C}(17)-\mathrm{H}(51)$ & 0.1097 & 0.1097 & 0.9168 & 0.9163 \\
\hline$C(10)-C(30)$ & $\begin{array}{c}0.154 \\
6\end{array}$ & $\begin{array}{c}0.154 \\
6\end{array}$ & $\begin{array}{c}0.995 \\
6\end{array}$ & $\begin{array}{c}0.996 \\
2\end{array}$ & $\mathrm{C}(18)-\mathrm{H}(52)$ & 0.1096 & 0.1095 & 0.9146 & 0.9134 \\
\hline $\mathrm{C}(9)-\mathrm{H}(42)$ & $\begin{array}{c}0.109 \\
7\end{array}$ & $\begin{array}{c}0.109 \\
8\end{array}$ & $\begin{array}{c}0.901 \\
5\end{array}$ & $\begin{array}{c}0.905 \\
5\end{array}$ & $\mathrm{C}(18)-\mathrm{H}(53)$ & 0.1097 & 0.1096 & 0.9179 & 0.9152 \\
\hline $\mathrm{C}(9)-\mathrm{H}(43)$ & $\begin{array}{c}0.109 \\
7\end{array}$ & $\begin{array}{c}0.110 \\
4\end{array}$ & $\begin{array}{c}0.901 \\
8\end{array}$ & $\begin{array}{c}0.914 \\
9\end{array}$ & $\mathrm{C}(19)-\mathrm{H}(54)$ & 0.1099 & 0.1099 & 0.9014 & 0.9007 \\
\hline $\mathrm{C}(7)-\mathrm{C}(14)$ & $\begin{array}{c}0.156 \\
9\end{array}$ & $\begin{array}{c}0.152 \\
9\end{array}$ & $\begin{array}{c}0.956 \\
6\end{array}$ & $\begin{array}{c}0.958 \\
8\end{array}$ & $\mathrm{C}(1)-\mathrm{C}(31)$ & 0.1546 & 0.1549 & 0.9980 & 0.9970 \\
\hline$C(14)-C(15)$ & $\begin{array}{c}0.152 \\
3\end{array}$ & $\begin{array}{c}0.152 \\
1\end{array}$ & $\begin{array}{c}0.987 \\
4\end{array}$ & $\begin{array}{c}0.991 \\
3\end{array}$ & $\mathrm{C}(1)-\mathrm{C}(23)$ & 0.1515 & 0.1515 & 1.0142 & 1.0137 \\
\hline$C(15)-C(16)$ & $\begin{array}{c}0.153 \\
1\end{array}$ & $\begin{array}{c}0.157 \\
3\end{array}$ & $\begin{array}{c}0.982 \\
7\end{array}$ & $\begin{array}{c}0.970 \\
6\end{array}$ & $\mathrm{C}(23)-\mathrm{C}(24)$ & 0.1349 & 0.1349 & 1.8252 & 1.8248 \\
\hline $\mathrm{C}(16)-\mathrm{C}(8)$ & $\begin{array}{c}0.159 \\
7\end{array}$ & $\begin{array}{c}0.160 \\
7\end{array}$ & $\begin{array}{c}0.947 \\
8\end{array}$ & $\begin{array}{c}0.947 \\
9\end{array}$ & $\mathrm{C}(24)-\mathrm{C}(2)$ & 0.1456 & 0.1456 & 1.1301 & 1.1303 \\
\hline $\mathrm{C}(14)-\mathrm{O}(25)$ & $\begin{array}{c}0.143 \\
0\end{array}$ & $\begin{array}{c}0.146 \\
2\end{array}$ & $\begin{array}{c}0.930 \\
2\end{array}$ & $\begin{array}{c}0.871 \\
5\end{array}$ & $\mathrm{C}(2)-\mathrm{C}(4)$ & 0.1355 & 0.1355 & 1.7714 & 1.7712 \\
\hline $\mathrm{C}(15)-\mathrm{H}(48)$ & $\begin{array}{c}0.109 \\
3\end{array}$ & $\begin{array}{c}0.109 \\
2\end{array}$ & $\begin{array}{c}0.879 \\
2\end{array}$ & $\begin{array}{c}0.884 \\
4\end{array}$ & $\mathrm{C}(4)-\mathrm{C}(3)$ & 0.1511 & 0.1511 & 1.0297 & 1.0298 \\
\hline
\end{tabular}

Table 5. The calculation of bond length and bond order of compound 3 and 4.

\begin{tabular}{|c|c|c|c|c|c|c|c|c|c|}
\hline \multirow{2}{*}{ Position } & \multicolumn{2}{|c|}{ Bond Length /nm } & \multicolumn{2}{|c|}{ Bond order } & \multirow{2}{*}{ Position } & \multicolumn{2}{|c|}{ BondLength/nm } & \multicolumn{2}{|c|}{ Bond order } \\
\hline & 3 & 4 & 3 & 4 & & 3 & 4 & 3 & 4 \\
\hline \multirow{2}{*}{$\mathrm{C}(7)-\mathrm{H}(37)$} & 0.110 & 0.110 & 0.857 & 0.842 & \multirow{2}{*}{$\mathrm{C}(15)-\mathrm{H}(45)$} & \multirow{2}{*}{0.1096} & \multirow{2}{*}{0.1094} & \multirow{2}{*}{0.8715} & \multirow{2}{*}{0.8753} \\
\hline & 7 & 6 & 3 & 8 & & & & & \\
\hline \multirow{2}{*}{$\mathrm{C}(6)-\mathrm{C}(7)$} & 0.150 & 0.151 & 0.997 & 0.997 & \multirow{2}{*}{$\mathrm{C}(15)-\mathrm{H}(46)$} & \multirow{2}{*}{0.1096} & \multirow{2}{*}{0.1098} & \multirow{2}{*}{0.8870} & \multirow{2}{*}{0.8840} \\
\hline & 8 & 4 & 7 & 8 & & & & & \\
\hline \multirow{2}{*}{$\mathrm{C}(6)-\mathrm{C}(13)$} & 0.135 & 0.135 & 1.748 & 1.794 & \multirow{2}{*}{ C(16)-C(28) } & \multirow{2}{*}{0.1539} & \multirow{2}{*}{0.1528} & \multirow{2}{*}{1.0061} & \multirow{2}{*}{1.0101} \\
\hline & 5 & 2 & 9 & 1 & & & & & \\
\hline \multirow{2}{*}{$C(13)-C(12)$} & 0.150 & 0.151 & 1.044 & 1.029 & \multirow{2}{*}{$\mathrm{C}(16)-\mathrm{O}(24)$} & \multirow{2}{*}{0.1463} & \multirow{2}{*}{0.1474} & \multirow{2}{*}{0.9053} & \multirow{2}{*}{0.8934} \\
\hline & 4 & 0 & 6 & 8 & & & & & \\
\hline \multirow{2}{*}{$\mathrm{C}(12)-\mathrm{C}(11)$} & 0.154 & 0.156 & 0.995 & 0.978 & \multirow{2}{*}{$\mathrm{C}(6)-\mathrm{C}(20)$} & \multirow{2}{*}{0.1484} & \multirow{2}{*}{0.1495} & \multirow{2}{*}{1.0764} & \multirow{2}{*}{1.0499} \\
\hline & 1 & 4 & 1 & 0 & & & & & \\
\hline \multirow{2}{*}{$\mathrm{C}(11)-\mathrm{C}(10)$} & 0.156 & 0.157 & 0.969 & 0.970 & $\Gamma(20) \Omega(2)$ & 01242 & 01213 & 17883 & 17027 \\
\hline & 7 & 0 & 5 & 0 & $C(20)-U(\angle L)$ & 0.1242 & 0.1243 & 1.1883 & 1.1921 \\
\hline
\end{tabular}




\begin{tabular}{|c|c|c|c|c|c|c|c|c|c|}
\hline $\mathrm{C}(10)-\mathrm{C}(9)$ & $\begin{array}{c}0.157 \\
2 \\
\end{array}$ & $\begin{array}{c}0.155 \\
4 \\
\end{array}$ & $\begin{array}{c}0.982 \\
7\end{array}$ & $\begin{array}{c}0.988 \\
1\end{array}$ & $\mathrm{C}(10)-\mathrm{C}(17)$ & 0.1558 & 0.1555 & 0.9795 & 0.9780 \\
\hline $\mathrm{C}(9)-\mathrm{C}(8)$ & $\begin{array}{c}0.155 \\
9\end{array}$ & $\begin{array}{c}0.154 \\
9\end{array}$ & $\begin{array}{c}1.003 \\
5\end{array}$ & $\begin{array}{c}0.994 \\
6\end{array}$ & $\mathrm{C}(17)-\mathrm{C}(18)$ & 0.1539 & 0.1544 & 1.0086 & 1.0088 \\
\hline $\mathrm{C}(8)-\mathrm{C}(7)$ & $\begin{array}{c}0.157 \\
0\end{array}$ & $\begin{array}{c}0.155 \\
6\end{array}$ & $\begin{array}{c}0.960 \\
2\end{array}$ & $\begin{array}{c}0.981 \\
1\end{array}$ & $\mathrm{C}(18)-\mathrm{C}(19)$ & 0.1558 & 0.1563 & 0.9936 & 0.9906 \\
\hline $\mathrm{C}(8)-\mathrm{H}(38)$ & $\begin{array}{c}0.109 \\
9\end{array}$ & $\begin{array}{c}0.109 \\
6\end{array}$ & $\begin{array}{c}0.898 \\
8\end{array}$ & $\begin{array}{c}0.889 \\
9\end{array}$ & $\mathrm{C}(19)-\mathrm{C}(11)$ & 0.1597 & 0.1592 & 0.9732 & 0.9774 \\
\hline $\mathrm{C}(13)-\mathrm{H}(44)$ & $\begin{array}{c}0.109 \\
1\end{array}$ & $\begin{array}{c}0.109 \\
1\end{array}$ & $\begin{array}{c}0.889 \\
5\end{array}$ & $\begin{array}{c}0.887 \\
3\end{array}$ & $\mathrm{C}(19)-\mathrm{C}(1)$ & 0.1558 & 0.1554 & 0.9889 & 0.9898 \\
\hline $\mathrm{C}(12)-\mathrm{H}(42)$ & $\begin{array}{c}0.110 \\
4\end{array}$ & $\begin{array}{c}0.109 \\
3\end{array}$ & $\begin{array}{c}0.864 \\
8\end{array}$ & $\begin{array}{c}0.905 \\
6\end{array}$ & $\mathrm{C}(17)-\mathrm{H}(47)$ & 0.1095 & 0.1100 & 0.8905 & 0.9151 \\
\hline $\mathrm{C}(12)-\mathrm{H}(43)$ & $\begin{array}{c}0.109 \\
5\end{array}$ & $\begin{array}{c}0.109 \\
5\end{array}$ & $\begin{array}{c}0.899 \\
9\end{array}$ & $\begin{array}{c}0.899 \\
3\end{array}$ & $\mathrm{C}(17)-\mathrm{H}(48)$ & 0.1098 & 0.1097 & 0.9189 & 0.9152 \\
\hline $\mathrm{C}(11)-\mathrm{H}(41)$ & $\begin{array}{c}0.108 \\
9\end{array}$ & $\begin{array}{c}0.109 \\
9\end{array}$ & $\begin{array}{c}0.895 \\
8 \\
\end{array}$ & $\begin{array}{c}0.898 \\
9\end{array}$ & $\mathrm{C}(18)-\mathrm{H}(49)$ & 0.1095 & 0.1094 & 0.9147 & 0.9141 \\
\hline $\mathrm{C}(10)-\mathrm{C}(21)$ & $\begin{array}{c}0.105 \\
1 \\
\end{array}$ & $\begin{array}{c}0.154 \\
7 \\
\end{array}$ & $\begin{array}{c}0.995 \\
6 \\
\end{array}$ & $\begin{array}{c}0.994 \\
0 \\
\end{array}$ & $\mathrm{C}(18)-\mathrm{H}(50)$ & 0.1095 & 0.1096 & 0.9158 & 0.9146 \\
\hline C(9)-H(39) & $\begin{array}{c}0.110 \\
1\end{array}$ & $\begin{array}{c}0.109 \\
9\end{array}$ & $\begin{array}{c}0.911 \\
4\end{array}$ & $\begin{array}{c}0.909 \\
8\end{array}$ & $\mathrm{C}(19)-\mathrm{H}(51)$ & 0.1098 & 0.1099 & 0.9002 & 0.8999 \\
\hline $\mathrm{C}(9)-\mathrm{H}(40)$ & $\begin{array}{c}0.109 \\
8\end{array}$ & $\begin{array}{c}0.110 \\
2\end{array}$ & $\begin{array}{c}0.906 \\
9\end{array}$ & $\begin{array}{c}0.914 \\
6\end{array}$ & $\mathrm{C}(1)-\mathrm{C}(27)$ & 0.1552 & 0.1548 & 0.9953 & 0.9991 \\
\hline $\mathrm{C}(7)-\mathrm{C}(14)$ & $\begin{array}{c}0.153 \\
5\end{array}$ & $\begin{array}{c}0.154 \\
4\end{array}$ & $\begin{array}{c}0.964 \\
0\end{array}$ & $\begin{array}{c}0.955 \\
9\end{array}$ & $\mathrm{C}(1)-\mathrm{C}(25)$ & 0.1520 & 0.1521 & 1.0202 & 1.0195 \\
\hline $\mathrm{C}(14)-\mathrm{C}(15)$ & $\begin{array}{c}0.152 \\
4\end{array}$ & $\begin{array}{c}0.151 \\
9\end{array}$ & $\begin{array}{c}0.990 \\
3\end{array}$ & $\begin{array}{c}0.994 \\
8\end{array}$ & $C(25)-C(26)$ & 0.1349 & 0.1349 & 1.8199 & 1.8188 \\
\hline $\mathrm{C}(15)-\mathrm{C}(16)$ & $\begin{array}{c}0.154 \\
1\end{array}$ & $\begin{array}{c}0.153 \\
5\end{array}$ & $\begin{array}{c}0.983 \\
8\end{array}$ & $\begin{array}{c}0.984 \\
9\end{array}$ & $C(26)-C(2)$ & 0.1457 & 0.1457 & 1.1275 & 1.1285 \\
\hline $\mathrm{C}(16)-\mathrm{C}(8)$ & $\begin{array}{c}0.158 \\
3\end{array}$ & $\begin{array}{c}0.157 \\
1\end{array}$ & $\begin{array}{c}0.954 \\
4\end{array}$ & $\begin{array}{c}0.961 \\
6\end{array}$ & $\mathrm{C}(2)-\mathrm{C}(4)$ & 0.1355 & 0.1355 & 1.7728 & 1.7717 \\
\hline $\mathrm{C}(14)-\mathrm{O}(23)$ & $\begin{array}{c}0.123 \\
6\end{array}$ & $\begin{array}{c}0.123 \\
5\end{array}$ & $\begin{array}{c}1.838 \\
2\end{array}$ & $\begin{array}{c}1.845 \\
8\end{array}$ & C(4)-C(3) & 0.1511 & 0.1511 & 1.0296 & 1.0298 \\
\hline
\end{tabular}

\subsection{Analysis of optimization results}

Table 6 shows the bond length of $\mathrm{C}(7)-\mathrm{H}(40)$ in 1 (0.1097 nm) was shorter than $2(0.1104 \mathrm{~nm})$, which confirmed that the bond energy of $\mathrm{C}(7)-\mathrm{H}(40)$ in 1 was higher than 2, and 1 was better than 2 in the thermodynamic stability of this chem- ical bond. Also the bond order of $\mathrm{C}(7)-\mathrm{H}(40)$ in 1 (0.8810) was bigger than 2 (0.8525), suggested that the bond energy of $\mathrm{C}(7)-\mathrm{H}(40)$ in 1 was higher than 2. It also supported that 1 was better than 2 in the thermodynamic stability. The overall energy of the molecular of 1(-1354.6121) was lower than 2(-1354.5984), It was con- 
firmed that the chemical stability of 1 was higher than 2 . In conclusion, 1 was superior to 2 both from the thermodynamic stability and chemical stability, and it also indicated that the steric hindrance of 1 was less than 2 .

Using the same method, the bond length of $\mathrm{C}(7)-\mathrm{H}(37)$ in 3 and 4 were basically the same, while the bond order of $\mathrm{C}(7)-\mathrm{H}(37)$ of 3 was still bigger than 2, suggested that the bond energy of $\mathrm{C}(7)-\mathrm{H}(37)$ in 3 was higher than 4, and had higher thermodynamic stability in this position. Also, the bigger bond order of $\mathrm{C}(7)-\mathrm{H}(37)$ of 3
(0.8573) suggested that the bond energy of $\mathrm{C}(7)-\mathrm{H}(37)$ of 3 was higher than 4 . It also indicated that the thermodynamic stability in this bond of 3 was better than 4 . The overall energy of the molecular indicated that the overall molecular chemical stability of 4 was better than 3 , it was interesting result that 3 had more thermodynamic stability than 4 on the key structure of $C(7)$, but the chemical stability of the overall molecular of 3 was weaker than 4. It indicated that the whole steric hindrance of 3 was higher than 4 , but in the position $\mathrm{C}(7)-\mathrm{H}(37)$, it showed opposite result that the steric hindrance of 3 was less than 4 .

Table 6. Theoretical calculation of the basic parameters of ophiobolin.

\begin{tabular}{|l|c|c|l|c|c|}
\hline \multicolumn{1}{|c|}{ Compound } & $\mathrm{O}(1)$ & $\mathrm{O}(2)$ & \multicolumn{1}{c|}{ 名称 } & $\mathrm{K}(3)$ & $\mathrm{K}(4)$ \\
\hline Bond Length of $(7)-\mathrm{H}(40)(\mathrm{nm})$ & 0.1097 & 0.1104 & Bond Length of $(7)-\mathrm{H}(37)(\mathrm{nm})$ & 0.1107 & 0.1106 \\
\hline Bond order of $\mathrm{C}(7)-\mathrm{H}(40)$ & 0.8810 & 0.8525 & Bond order of $\mathrm{C}(7)-\mathrm{H}(37)$ & 0.8573 & 0.8428 \\
\hline Overall energy (hartree) & -1354.6121 & -1354.5984 & Overall energy (hartree) & -1199.6120 & -1199.6223 \\
\hline
\end{tabular}

The optimized whole molecular energy analysis suggested opposite results in molecular integral steric hindrance of compounds 1, 2 and 3, 4. It was hard to explain the bioactivity regularities of ophiobolins using the whole molecular steric hindrance method. But in the position $C(7)$, all the analysis showed the same pattern, both lower steric hindrance and strong biological activity. It determined that the $C(7)$ was one bioactive functional group in the ophiobolins. The steric hindrance size directly affected the biological activity of compounds. The compounds attacking the target should be much easier within smaller steric hindrance size and showed higher bioactivity.

It was also easily understood that the overall steric hindrance of 3 and 4 didn't follow this rule. Not all the functional groups in the molecule 3 and 4 were key bioactive functional groups. It suggested that the steric hindrance determination of partial functional groups could be used as one criterion to find bioactive functional groups of target compounds.

\section{Conclusions}

According to a systematic review of the ophiobolin family members that have been found, give a brief introduction including resource, structure, bioactivity, The mode of action and the possible reasons that cause the different bioactivity. Taking ophiobolin $\mathrm{O}, \mathrm{K}$ and 6-epi-ophiobolin $\mathrm{O}, \mathrm{K}$ as an example, which had the same planar 
structures but different activity, according to calculate the bond lengths and bond orders, together with whole molecular energy using density functional theory at $B 3 L Y P / 6-31+G(d, p)$ level, It was found that the steric hindrance of active functional groups was the key factor of bioactivity. The functional groups with low steric hindrance could be easier attacking the target, and thereby enhance the compounds bioactivity.

\section{References:}

[1] Parminder K. Ruprah, Jean-Philippe Cros, J. Elizabeth Pease, William G Whittingham, and Jonathan M. J. Williams. Studies Towards the Total Synthesis of Cycloaraneosene and Ophiobolin M: A General Strategy for the Construction of the 5-8 Bicyclic Ring System. Eur. J. Org. Chem. 2002, 3145-3152.

[2] T.K. Au, Wallace S.H. Chick, P.C. Leung. The biology of ophiobolins, Life Sciences 67 (2000) 733-742.

[3] Tanja Thorskov Bladt, Claudia Dürr, Peter Boldsen Knudsen, Sara Kildgaard, Jens ChristianFrisvad, Charlotte Held Gotfredsen, Martina Seiffert, and Thomas Ostenfeld Larsen, Bio-Activity and Dereplication-Based Discovery of Ophiobolins and Other Fungal Secondary Metabolites Targeting Leukemia Cells. Molecules 2013, 18, 14629-14650.

[4] Michikazu N, Keijiro I. On the new antibiotics Ophiobplin, produced by Ophiobolus Miyabeanus. J. Agri. Chem. Soc. Jpn, 1958, $32,739-744$.

[5] Canonica, L.; Fiecchi, A.; Galli Kienle, M.;
Scala, A. The costitution of cochliobolin. Tetrahedron Lett. 1966, 1211-1218.

[6] Nozoe, S.; Hirai, K.; Tsuda, K. The structure of zizanin- $A$ and $-B, C 25$-terpenoids isolated from Helm-inthosporium zizaniae.Tetrahedron Lett. 1966, 2211-2216.

[7] Canonica, L.; Fiecchi, A.; Galli Kienle, M.; Scala, A. Isolation and constitution of cochliobolin. Tetrahedron Lett. 1966, 1329-1333.

[8] Itai, A.; Nozoe, S.; Tsuda, K.; Okuda, S.; litaka, Y.; Makayama, Y. The structure of cephalonic acid, a pentaprenyl terpenoid. Tetraedron Lett. 1967, 4111-4112.

[9] Nozoe, S.; Itai, A.; Tsuda, K.; Okuda, S. Chemical transformation of cephalonic acid. Tetrahedron Lett. 1967, 4113-4117.

[10] Antonio Evidente, Anna Andolfi, Alessio Cimmino, Maurizio Vurro, Mariano Fracchiolla, Raghavan Charudattan, Andrea Motta. Ophiobolin E and 8-epi-ophiobolin J produced by Drechslera gigantea, a potential mycoherbicide of weedy grasses. Phytochemistry 67 (2006) 2281-2287.

[11] Nozoe, S.; Morisaki, M.; Fukushima, K.; Okuda, S. The isolation of an acyclic C25-isoprenoid alcohol, geranylnerolidol, and a new ophiobolin Tetrahedron Lett. 1968, 4457-4458.

[12] Horace G. Cutler, Farrist G. Crumley, Richard H. Cox, James P. Springer, Richard F. Arrendale, Richard J. Cole, Patsy D. Cole. Ophiobolins $G$ and $H$ : New Fungal Metabolites from a Novel Source, Aspergillusust ustus. J. Agric. Food Chem. 1984,32,778782.

[13] Fumio Sugawara and Nobutaka Takahashi, 
RIKEN, Wako, Saitama 351-01, Japan, Gary Strobel and Choong-Hyo Yun. Some New Phytotoxic Ophiobolins Produced by Drechslera oryzae. Journal of Organic Chemistry .1988, 53 (10):2170-2172.

[14] Camila Rodrigues de Carvalho, Mariana de Lourdes Almeida Vieira, Charles L. Cantrell, David E. Wedge, Tânia M.A. Alves, Carlos Leomar Zani, Raphael Sanzio Pimenta, Policarpo A. Sales Junior, Silvane M.F. Murta, Alvaro J. Romanha, Carlos Augusto Rosa \& Luiz H. Rosa. Biological activities of ophiobolin $\mathrm{K}$ and 6-epiophiobolin $\mathrm{K}$ produced by the endophytic fungus Aspergillus calidoustus. Natural Product Research, 2016.Vol. 30, No. 4, 478-481.

[15] Athanasios Tsipouras, Akinlolu A. Adefarati, Jan S. Tkacz, Easter G. Frazier, Susan P. Rohrer, Elizabeth Birzin, Avery Rosegay, Deborah L. Zink, Michael A. Goetz, Sheo B. Singh and James M. Schaeffer. Ophiobolin $\mathrm{M}$ and Analogues, Noncompetitive Inhibitors of Ivermectin Binding with Nematocidal Activity. Bioorganic \& Medicinal Chemistry, Vol. 4, No. 4. pp. 531-536, 1996.

[16] Tingting Yang, Zhenyu Lu, Li Meng, Shanjian Wei, Kui Hong, Weiming Zhu,Caiguo Huang. The novel agent ophiobolin $\mathrm{O}$ induces apoptosis and cell cycle arrest of MCF-7 cells through activation of MAPK signaling pathways. Bioorganic \& Medicinal Chemistry Letters 22 (2012) 579-585.

[17] Quan-Xin Wang, Li Bao, Xiao-Li Yang, Dai-Lin Liu, Hui Guo, Huan-Qin Dai, Fu-Hang Song, Li-Xin Zhang, Liang-Dong Guo, Shao-Jie Li, Hong-Wei Liu. Ophiobolins $\mathrm{P}-\mathrm{T}$, five new cytotoxic and antibacterial sesterterpenes from the endolichen- ic fungus Ulocladium sp. Fitoterapia 90 (2013) 220-227.

[18] Xiang-Hong Liu, Feng-Ping Miao, Ming-Feng Qiao, Robert $\mathrm{H}$. Cichewicz and Nai-Yun Ji. Terretonin, ophiobolin, and drimane terpenes with absolute configurations from an algicolous Aspergillus ustus. RSC Adv., 2013, 3, 588-595.

[19] Blunt, J. W.; Copp, B. R.; Munro, M. H.; Northcote, P. T.; Prinsep, M. R. Marine natural products. Nat. Prod. Rep. 2009, 22, 170-244.

[20] MARINA BURY, ESTHER NOVO-UZAL, ANNA ANDOLFI, SARA CIMINI, NATHALIE WAUTHOZ, PETRA HEFFETER et al. Ophiobolin A, a sesterterpenoid fungal phytotoxin, displays higher in vitro growth-inhibitory effects in mammalian than in plant cells and displays in vivo antitumor activity. INTERNATIONAL JOURNAL OF ONCOLOGY 43: 575-585, 2013.

[21] Preecha Phuwapraisirisan, Knokwan Sawang, Pongpun Siripong and Santi Tip-pyang. Anhydrocochlioquin-one $\mathrm{A}, \mathrm{a}$ new antitumor compound from Bipolaris oryzae. Tetrahedron Letters 48 (2007) 5193-5195.

[22] Hong Wei, Takuya Itoh, Masahiro Kinoshita, Yasuhide Nakai, Mineko Kurotaki and Motomasa Kobayashi. Cytotoxic sesterterpenes, 6-epi-ophiobolin $G$ and 6-epi-ophiobolin $\mathrm{N}$, from marine derived fungus Emericella variecolor GF10. Tetrahedron 60 (2004) 6015-6019.

[23] Hyun-Ju Kim, Jin-Cheol Kim, Byung Sup Kim, Hong Gi Kim and Kwang Yun Cho. Antibiotic and Phytotoxic Activities of Ophiobolins from Helminthosporium Species. Plant Pa- 
thol. J. 15(1): 14-20 (1999).

[24] Koji Narita, Ryota Chiba, Atsushi Minami, Motoichiro Kodama, Isao Fujii, Katsuya Gomi, and Hideaki Oikawa. Multiple Oxidative Modifications in the Ophiobolin Biosynthesis:P450 Oxidations Found in Genome Mining. Org. Lett. 2016, 18, 1980-1983.

[25] Kazuhiro Tsuna, Naoyoshi Noguchi, and Masahisa Nakada. Enantioselective Total Synthesis of (+)-Ophiobolin A. Chem. Eur. J. 2013, 19, 5476-5486.

[26] Naoyoshi Noguchi and Masahisa Nakada. Synthetic Studies on (+)-Ophiobolin A:Asymmetric Synthesis of the Spirocyclic CD-Ring Moiety. ORGANIC LETTERS 2006 Vol. 8, No. 10 2039-2042.

[27] Zachary G. Brill, Huck K. Grover, Thomas J. Maimone. Enantioselective synthesis of an ophiobolin sesterterpene via a programmed radical cascade. ORGANIC CHEMISTRY 27 MAY 2016 • VOL 352 ISSUE 6289.

[28] Ke Li, Cheng Wang, Gang Yin and Shuanhu Gao. Construction of the basic skeleton of ophiobolin A and Variecolin. Org. Biomol. Chem., 2013, 11,7550.

[29] Robert M. Coates, Jack W. Muskopf, and Peter A. Senter. Synthesis of Stereoisomeric 4,9a-Dimethylhydrodicyclopenta[a,d]cycloocten-1-ones Related to the Ophiobolins and Ceroplastins via Annelative Ring Expansion of Hydrindene Precursors. J. Org. C hem. 1985,50, 3541-3557.

[30] Galluzzi L, Vitale I, Abrams JM, Alnemri ES, Baehrecke EH, Blagosklonny MV, Dawson TM, Dawson VL, El-Deiry WS, Fulda S, et al:
Molecular definitions of cell death subroutines: Recommendations of the Nomenclature Committee on Cell Death 2012. Cell Death Differ 19: 107-120, 2012.

[31] HIRONORI FUJIWARA, KIMIHIRO MATSUNAGA, HIROYUKI KUMAGAI, MASAAKI ISHIZUKA AND YASUSHI OHIZUMI. Ophiobolin A, a Novel Apoptosis-inducing Agent from Fungus Strain f-7438. Pharmacy \& Pharmacology Communications , 2000 , 6 (9) :427-431.

[32] Dimple R. Bhatia, Payal Dhar, Varun Mutalik, Sunil Kumar Deshmukh, Shilpa A. Verekar, Dattatraya C. Desai, Rajendra Kshirsagar, Padma Thiagarajan and Veena Agarwal. Anticancer activity of Ophiobolin $A$, isolated from the endophytic fungus Bipolaris setariae. NATURAL PRODUCT RESEARCH, 2016 VOL. 30, NO. 12, 1455-1458.

[33] Rachel Morrison, Chris Gardiner, Antonio Evidente, Robert Kiss, Helen Townley. Incorporation of Ophiobolin A into Novel Chemoembolization Particles for Cancer Cell Treatment. Pharm Res (2014) 31:2904-2917.

[34] Carlo Rodolfo, Mariapina Rocco, Lucia Cattaneo, Maria Tartaglia, Mauro Sassi, Patrizia Aducci, Andrea Scaloni, Lorenzo Camoni, Mauro Marra. Ophiobolin A Induces Autophagy and Activates the Mitochondrial Pathway of Apoptosis in Human Melanoma Cells. PLOS ONE, December 9, 2016.

[35] M Bury, A Girault, V Mégalizzi, S Spiegl-Kreinecker, V Mathieu, W Berger, A Evidente, A Kornienko, P Gailly, C Vandier and $\mathrm{R}$ Kiss. Ophiobolin A induces paraptosis-like cell death in human glioblastoma 
cells by decreasing BKCa channel activity. Cell Death and Disease (2013) , 4, e561.

[36] Christopher Chidley, Sunia A Trauger, Kıvanc, Birsoy, Erin K O'Shea. The anticancer natural product ophiobolin $A$ induces cytotoxicity by covalent modification of phosphatidylethanolamine. elife 2016; 5:e14601.

[37] Vittoria Locato, Esther Novo Uzal, Sara Cimini, Maria Chiara Zonno, Antonio Evidente, Alessandra Micera, Christine $\mathrm{H}$. Foyer and Laura De Gara. Low concentrations of the toxin ophiobolin A lead to an arrest of the cell cycle and alter the intracellular partitioning of glutathione between the nuclei and cytoplasm. Journal of Experimental Botany, Vol. 66, No. 10 pp. 2991-3000, 2015.

[38] Anikó Pósa, Renáta Szabó, Zita Szalai, Krisztina Kupai, Zoltán Deim, Zsolt Murlasits, OttóBencsik, András Szekeres, Csaba Vágvölgyi, László Balogh, Béla Juhász, Zoltán Szilvássy and Csaba Varga. The effect of acute ophiobolin A treatment on HO-mediated inflammatory processes. Human \& Experimental Toxicology July 13 , 2016.

[39] In Young Kim, MiRi Kwon, Min-Koo Choi, Dongjoo Lee, Dong Min Lee, Min Ji Seo and Kyeong Sook Choi. Ophiobolin A kills human glioblastoma cells by inducing endoplasmic reticulum stress via disruption of thiol proteostasis. Oncotarget, 2017, Vol. 8, (No. 63), pp: 106740-106752.

[40] Rachel Morrison, Tiffany Lodge, Antonio Evidente, Robert Kiss and Helen Townley. Ophiobolin A, a sesterpenoid fungal phytotoxin, displays different mechanisms of cell death in mammalian cells depending upon the cancer cell origin. INTERNATIONAL JOURNAL OF ONCOLOGY 50: 773-786, 2017.

[41] Xiaoyu Shen, Stuart B. Krasnoff, Shun-Wen Lu, Chuck D. Dunbar, James O'Neal, B. GilIan Turgeon, Olen C. Yoder, Donna M. Gibson, and Mark T. Hamann. Characterization of 6-epi-3-Anhydroophiobolin B from Cochliobolus Heterostrophus. J. Nat. Prod. 1999, 62, 895-897.

[42] Ottó Bencsik, Tamás Papp, Máté Berta, Annamária Zana, Péter Forgó, György Dombi, Maria A. Andersson, Mirja Salkinoja-Salonen, Csaba Vágvölgyi and András Szekeres. Ophiobolin A from Bipolaris oryzae Perturbs Motility and Membrane Integrities of Porcine Sperm and Induces Cell Death on Mammalian Somatic Cell Lines. Toxins 2014, 6, 2857-2871.

[43] Danfeng Xue, Quanxin Wang , Ziheng Chen, Lei Cai, Li Bao, Qiuyue Qi, Lei Liu, Xiaohui Wang, Haijing Jin, Jun Wang, Hao Wu, Hongwei Liu, Quan Chen. 3-Anhydro-6-hydroxy-ophiobolin A, a fungal sesterterpene from Bipolaris oryzae induced autophagy and promoted the degradation of $\alpha$-synuclein in PC12 cells. Bioorganic \& Medicinal Chemistry Letters 25 (2015) 1464-1470.

[44] Cuiting Lv, Wenxing Qin, Tonghan Zhu, Shanjian Wei, Kui Hong, Weiming Zhu, Ruohua Chen and Caiguo Huang. Ophiobolin $\mathrm{O}$ Isolated from Aspergillus ustus Induces G1 Arrest of MCF-7 Cells through Interaction with AKT/GSK3 $\beta /$ Cyclin D1 Signaling. Mar. Drugs 2015, 13, 431-443.

[45] MóNICA FERNÁNDEZ-APARICIO, ANNA ANDOLFI, ALESSIO CIMMINO, DIEGO RUBIALES, AND ANTONIO EVIDENTE, Stimu- 
lation of Seed Germination of Orobanche Species by Ophiobolin A and Fusicoccin Derivatives. J. Agric. Food Chem. 2008, 56, 8343-8347.

[46] Tai Kong Au and Pak Chow Leung, Identification of the Binding and Inhibition Sites in the Calmodulin Molecule for Ophiobolin A by Site-Directed Mutagenesis. Plant Physiol. (1998) 118: 965-973.

[47] T.K. Au, Wallace S.H. Chick, P.C. Leung. Initial kinetics of the inactivation of calmodulin by the fungal toxin ophiobolin A. Biochemistry \& Cell Biology 32 (2000) 1173-1182.

[48] Pak C. Leung, William A. Taylorg, Jerry H. Wang, and Carl L. Tipton. Ophiobolin A. THE JOURNAL OF BIOLOGICAL CHEMISTRY. Vol. 259, No. 5, Issue of March 10, pp. 2742-2747, 1984.

[49] Yoshito Fukushima, Youji Sakagami, Shingo Marumo. $\beta$-Glucan biosynthesis inhibitors isolated from fungi as hyphal malformation inducer. Bioorganic \& Medicinal Chemistry Letters.3 1219-1222(1993).

[50] Luciana Gianani, Sergio Cocucci, Daniela Pardi, and Giacomino Randazzo. Effects of Ophiobolin B on Cell Enlargement and $\mathrm{H}^{+} / \mathrm{K}^{+}$Exchange in Maize Coleoptile Tissues. Planta 146, 271-274 (1979).

[51] Krizsán, K.; Bencsik, O.; Nyilasi, I.; Galgóczy, L.; Vágvölgyi, C.; Papp, T. Effect of the sesterterpene-type metabolites, ophiobolins $A$ and $B$, on zygomycetes fungi. FEMS Microbiol Lett 313(2010) 135-140.

[52] Erguang Li, Alice M. Clark, David P. Rotella, and Charles D. Hufford. Microbial Metabolites of Ophiobolin A and Antimicrobial
Evaluation of Ophiobolins. J. Nat. Prod. 58 (1995) 74-81.

[53] Song Wang, Xiaoqin Luo, Ruoxiang Yan, Quanxin Wang, Qiuyue Qi, Xiaojuan Chi, Lanlan Zhang, Ziding Yu, Binxiang Cai, Ji-Long Chen, Hongwei Liu. 3-Anhydro-6-hydroxy-ophiobolin A displays high in vitro and in vivo efficacy against influenza A virus infection. Protein Cell 2016, 7(11):839-843.

[54] Natthapat Sohsomboon, Hiroshi Kanzaki and Teruhiko Nitoda, Unique antimicrobial spectrum of ophiobolin $\mathrm{K}$ produced by Aspergillus ustus. Bioscience, Biotechnology, and Biochemistry, 2018. 82, NO. 3, 422-424.

[55] W. A. Hussin and W. M. El-Sayed. Synergic Interactions Between Selected Botanical Extracts and Tetracycline Against Gram Positive and Gram Negative Bacteria. Journal of Biological Sciences 11(7): 433-441, 2001.

[56] PAK C. LEUNG, WILLIAM A. TAYLOR, JERRY H. WANG, AND CARL L. TIPTON. Role of Calmodulin Inhibition in the Mode of Action of Ophiobolin A. Plant Physiol. (1985) 77, 303-308.

[57] ANTONIO EVIDENTE, ANNA ANDOLF, ALESSIO CIMMINO, MAURIZIO VURRO, MARIANO FRACCHIOLLA, AND RAGHAVAN CHARUDATTAN. Herbicidal Potential of Ophiobolins Produced by Drechslera gigantean. J. Agric. Food Chem. 2006, 54, 1779-1783.

[58] Alvaro José Romanha, Solange Lisboa de Castro, Maria de Nazaré Correia Soeiro1, et al: In vitro and in vivo experimental models for drug screening and develop- 
ment for Chagas disease. Memórias Do Instituto Oswaldo Cruz, 2010, 105 (2) :233-238.

[59] Sheo B.Singh, Jack L.Smith, Glory S.Sabnis, Anne W.Dombrowski, James M.Schaeffer, Michael A.Goetz, Gerald F.Bills. Structure and conformation of ophiobolin $\mathrm{K}$ and 6 epiophiobolin $\mathrm{K}$ from Aspergillus ustus as a nematocidal agent. Tetrahedron.47 6931-6938 (1991).

[60] Zhang, D. H.; Fukuzawa, S.; Satake, M.; Li, X. G.; Kuranaga, T.; Niitsu, A.; Yoshizawa, K.; Tachibana, K. Ophiobolin $\mathrm{O}$ and 6-epi-ophiobolin $\mathrm{O}$, two new cytotoxic sesterterpenes from the marine derived fungus Aspergillus sp. Nat. Prod. Comm. 2012, 7(11), 1411-1414.

[61] ZHU Jing-tong,FAN Yu-ling,LU Xin-hua,DONG Yue-sheng,ZHENG Zhi-hui,ZHANG Hua,HE Jian-gong. In vitro anti-tumor effect of ophiobollin from microorganism. Carcinogenesis,Teratogenesis \& Mutagenesis. 2007, 19(5), 388-391.

[62] Quan-Xin Wang, Jian-Ling Yang, Qiu-Yue Qi, Li Bao, Xiao-Li Yang, Miao-Miao Liu, Pei Huang, Li-Xin Zhang, Ji-Long Chen, Lei Cai, Hong-Wei

Liu.

3-Anhydro-6-hydroxy-ophiobolin A, a new sesterterpene inhibiting the growth of methicillin-resistant Staphylococcus aureus and inducing the cell death by apoptosis on K562, from the phytopathogenic fungus Bipolaris oryzae. Bioorganic \& Medicinal Chemistry Letters 23 (2013) 3547-3550.

[63] AHN, JONG-WOONG, MI-KYOUNG LEE, SANG-UN CHOI, CHONG-OCK LEE, and BYUNG-SUP KIM. Cytotoxic Ophiobolins Produced by Bipolaris sp. J. Microbiol. Bio- technol. (1998), 8(4), 406-408.

[64] Ramesh Dasari, Marco Masi, Romana Lisy, Marlène Ferdérin, Lance R. English, Alessio Cimmino, Véronique Mathieu, Andrew J. Brenner, John G. Kuhn, Steven T. Whitten, Antonio Evidente, Robert Kiss, Alexander Kornienko. Fungal metabolite ophiobolin A as a promising anti-glioma agent: In vivo evaluation, structure-activity relationship and unique pyrrolylation of primary amines. Bioorganic \& Medicinal Chemistry Letters 25 (2015) 4544-4548.

[65] Hong-Bing Liu, RuAngelie Edrada-Ebel, Rainer Ebel, Yao Wang, Barbara Schulz, Siegfried Draeger, Werner E. G. Müller, Victor Wray, Wen-Han Lin, Peter Proksch. Ophiobolin Sesterterpenoids and Pyrrolidine Alkaloids from the Sponge-Derived Fungus Aspergillus ustus. Volume 94,(2011)Pages 623-631.

[66] Hong-Bing Liu, RuAngelie Edrada-Ebel, Rainer Ebel, Yao Wang, Barbara Schulz, Siegfried Draeger, Werner E. G. M_ller, Victor Wray, Wen-Han Lin, and Peter Proksch. Ophiobolin Sesterterpenoids and Pyrrolidine Alkaloids from the Sponge-Derived Fungus Aspergillus ustus. Helvetica Chimica Acta-Vol. 94 (2011).

[67] Hongbing Liu, RuAngelie Edrada-Ebel, Rainer Ebel, Yao Wang, Barbara Schulz, Siegfried Draeger, Werner E. G. MÜller, Victor Wray, Wenhan Lin, and Peter Proksch, Drimane Sesquiterpenoids from the Fungus Aspergillus ustus Isolated from the Marine Sponge Suberites domuncula. J. Nat. Prod. 2009, 72, 1585-1588.

[68] G. S. Muromtsev, V. D. Voblikova, N. S. Kobrina, V. M. Koreneva, L. M. Krasnopolskaya, and V. L. Sadovskaya. Occurrence of 
Fusicoccanes in Plants and Fungi. J Plant Growth Regul (1994) 13:39-49.

[69] Lu, X. H.; Zheng, Z. H.; Ma, Y.; Shi, Y.; Dong, Y. S.; Ren, X.; Mu, D.; Zhang, H.; He, J. G. F02-2172, factor $X a$ inhibitors from metabolites of microorganisms. Chinese Journal of Antibiotics. 2007, 32(5), 277-279.

[70] Frisch, M. J.; Trucks, G. W.; Schlegel, H. B.; Scuseria, G. E.; Robb, M. A.; Cheeseman, J. R. Gaussian, Inc.: Pittsburgh, PA, 2009.

[71] Wallingford, C. T. 201017 Becke AD. Density-functional exchange-energy approximation with correct asymptotic behavior. Phys Rev A. 1988, 38: 3098-3100.
[72] Lee, C.; Yang, W.; Parr, R. G. Development of the Colle-Salvetti correlation- energy formula into a functional of the electron density. Phys Rev B. 1988, 37, 785-789.

[73] Weinhold, F.; Landis, C. R.; Valency and Bonding. A Natural Bond Orbital Donor-Acceptor Perspective. Cambridge University Press, 2005.

[74] Glendening, E.D., Badenhoop, J.K., Reed, A.E., Carpenter, J.E., Bohmann, J.A., Morales, C.M., Weinhold F. (2001) NBO 5.0. Theoretical Chemistry Institute, University of Wisconsin, Madison, WI, 2004. 